\title{
Novel Exosome Biomarker Candidates for Alzheimer's Disease Unravelled Through Mass Spectrometry Analysis
}

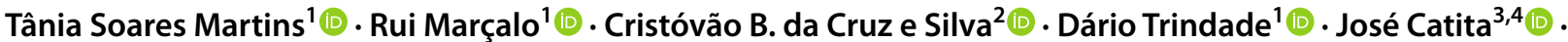

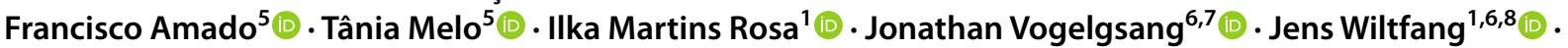 \\ Odete A. B. da Cruz e Silva ${ }^{1}\left[\right.$. Ana Gabriela Henriques ${ }^{1}(1)$
}

Received: 2 October 2021 / Accepted: 28 January 2022 / Published online: 25 February 2022

(c) The Author(s) 2022

\begin{abstract}
Exosomes are small extracellular vesicles (EVs) present in human biofluids that can transport specific disease-associated molecules. Consequently blood-derived exosomes have emerged as important peripheral biomarker sources for a wide range of diseases, among them Alzheimer's disease (AD). Although there is no effective cure for AD, an accurate diagnosis, relying on easily accessible peripheral biofluids, is still necessary to discriminate this disease from other dementias, test potential therapies and even monitor rate of disease progression. The ultimate goal is to produce a cost-effective and widely available alternative, which can also be employed as a first clinical screen. In this study, EVs with exosome-like characteristics were isolated from serum of Controls and $\mathrm{AD}$ cases through precipitation- and column-based methods, followed by mass spectrometry analysis. The resulting proteomes were characterized by Gene Ontology (GO) and multivariate analyses. Although GO terms were similar for exosomes' proteomes of Controls and ADs, using both methodologies, a clear segregation of disease cases was obtained when using the precipitation-based method. Nine significantly different abundant proteins were identified between Controls and AD cases, representing putative biomarker candidate targets. Among them are AACT and $\mathrm{C} 4 \mathrm{BP} \alpha$, two A $\beta$-binding proteins, whose exosome levels were further validated in individuals from independent cohorts using antibody-based approaches. The findings discussed represent an important contribution to the identification of novel exosomal biomarker candidates useful as potential blood-based tools for AD diagnosis.
\end{abstract}

Keywords Alzheimer's disease $\cdot$ Biomarkers $\cdot$ Blood $\cdot$ Diagnosis $\cdot$ Exosomes $\cdot$ Extracellular vesicles

\section{Introduction}

Alzheimer's disease (AD) is the most common form of dementia worldwide, and the number of individuals affected by this condition is expected to increase exponentially in the next decades. At the histopathological level,

Ana Gabriela Henriques

aghenriques@ua.pt

1 Neuroscience and Signalling Group, Department of Medical Sciences, Institute of Biomedicine (iBiMED), University of Aveiro (UA), 3810-193 Aveiro, Portugal

2 Laboratory of Instrumentation and Experimental Particle Physics-LIP, Av. Elias Garcia 14-1º $1000-149$ Lisbon, Portugal

3 CEBIMED—Faculty of Health Sciences, University Fernando Pessoa, 4249-004 Porto, Portugal

4 Paralab SA, 4420-437 Gondomar, Portugal
$\mathrm{AD}$ is characterized by the aggregation and accumulation of the amyloid-beta $(\mathrm{A} \beta)$ peptide into senile plaques and of the microtubule-associated protein Tau into neurofibrillary tangles [1]. These deposits occur as a consequence of abnormal phosphorylation events [2-4], and lead to neuronal death and synaptic dysfunction, as well as glial activation

5 Department of Chemistry, QOPNA (Organic Chemistry Natural and Agrofood Products and LAVQ REQUIMTE), University of Aveiro, 3810-193 Aveiro, Portugal

6 Department of Psychiatry and Psychotherapy, University Medical Center Goettingen (UMG), Georg-August University, Von-Siebold-Str. 5, 37075 Goettingen, Germany

7 Translational Neuroscience Laboratory, McLean Hospital, Harvard Medical School, Belmont, MA 02478, USA

8 German Center for Neurodegenerative Diseases (DZNE), Von-Siebold-Str. 3a, 37075 Goettingen, Germany 
and neuroinflammation [5], among other neurodegenerative events.

Despite the huge research efforts in the field, no effective treatment or cure is available thus far, and diagnosis is also challenging. $\mathrm{AD}$ diagnosis is based on clinical symptom evaluation, cognitive testing and brain imaging and, in some cases, supported by the molecular diagnostics, namely the monitoring of the gold standard biomarker triplet (A $\beta$, totalTau and P-Tau 181) in the cerebrospinal fluid (CSF) $[6,7]$. The latter neurochemical analysis has undeniable value in assisting AD differential diagnosis; nonetheless, it requires a lumbar puncture which is an invasive procedure, thus limiting its wide routine use or resource as a first screening tool. Hence, extensive research centered on the identification of biomarkers resorting to more easily accessible biofluids, like blood. Indeed, different molecular contents, including the biomarker triplet, have been tested in this peripheral biofluid [8]. Although currently, there are no reliable bloodbased biomarkers for $\mathrm{AD}$, this is urgently needed in clinical practice.

Recently, focus has been given to blood-derived exosomes in $\mathrm{AD}$, a subclass of extracellular vesicles (EVs) with a multivesicular endosomal origin, ranging from 30 to $150 \mathrm{~nm}$ in diameter. These nanovesicles are formed by the inward budding of the endosome membrane and further released through the fusion of multivesicular bodies with the plasma membrane [9]. Exosomes are secreted by various cell types and can carry relevant proteins, lipids and nucleic acids, reflecting the status of the cells from which these nanovesicles derived. These type of EVs, present in various body fluids besides blood (e.g. saliva or urine), would represent easily accessible and cost-effective tools as biomarker sources for monitoring disease status, but also as drug delivery vehicles for a set of diseases, including cancer and inflammatory and neurological diseases [10]. The lipid bilayer of exosomes ensures the stability of the cargo, protecting the content from enzyme degradation in the bloodstream. In addition, since exosomes are capable of crossing the blood-brain barrier due to their small size, these nanovesicles can be particularly useful to study brainrelated disorders [11].

In an $\mathrm{AD}$ context, exosomes carry disease specific-related signatures and contribute to the spreading of the amyloidogenic peptide species [12]. The biomarker value of these blood-derived exosomal vesicles has been tested, focusing on the levels of $A \beta$ and other amyloid precursor protein fragments, Tau and phosphorylated Tau species [13-15]. Synaptic proteins, inflammatory mediators, growth factors and lysosomal proteins also presented distinct expression patterns in exosomes from $\mathrm{AD}$ cases when compared to Controls [16-19]. In addition, specific microRNA [12, 20, 21], metabolic [22], or lipid profile [23] alterations have been reported.
In this work, mass spectrometry (MS) was used to identify new blood-derived exosomal biomarker candidates associated with AD-exosomal proteomes. MS is highly sensitive and, thus, allows an unbiased biomarker identification in biofluids [24]. Proteome profiles were characterized through Gene Ontology (GO) analysis, and putative exosomal biomarker candidates were identified and further validated for two distinct patient cohorts. Biomarker candidates that arise from this analysis can constitute novel tools, potentially useful in $\mathrm{AD}$ and/or dementia peripheral biofluidsbased diagnostics.

\section{Materials and Methods}

\section{Study Cohorts}

Blood samples were collected from individuals enrolled in a primary care-based cohort (pcb-cohort), which comprises volunteer individuals from the Baixo Vouga region of Aveiro. The inclusion and exclusion criteria were defined, and volunteers were submitted to a battery of cognitive tests as previously described $[25,26]$. The cognitive and functional performance of volunteers was categorized based on the score obtained in 2 cognitive tests, the Mini-Mental State Examination (MMSE) and the Clinical Dementia Rating (CDR). MMSE scale cutoffs were set according to Portuguese population: $0-2$ years of literacy, cutoff $=22$; 3-6 years of literacy, cutoff $=24$; and $\geq 7$ years of literacy, cutoff $=27$. Scores below the cutoff indicate possible cognitive impairment (MMSE + ), and scores equal or above were classified as normal (MMSE-). CDR scale applied scores between 0 and 3 , where 0 accounts for normal, 1 for mild dementia, 2 for moderate and 3 for severe dementia stages.

The pcb-cohort, herein designated as the UA-cohort, included a subgroup of 32 individuals that scored CDR $\geq 1$ and MMSE + (mean age 77.38 \pm 9.17$)$ and 9 clinically reported $\mathrm{AD}$ cases ( $1 \mathrm{AD}$ only scored $\mathrm{CDR}=1$ ), (mean age $78.67 \pm 5.07)$. Sex- and age-matched Controls $(C D R=0$ and MMSE -) were randomly selected from the same cohort $(n=32$, mean age $76.69 \pm 8.07$ and $n=9$, mean age $77.56 \pm 4.83)$.

Another independent cohort, established at the Department of Psychiatry and Psychotherapy at the University Medical Center Goettingen (UMG-cohort), was also used for biomarker candidate's validation. The UMG-cohort study group comprises 12 age-matched Controls (mean age $67.58 \pm 7.74)$ and 12 demented individuals clinically diagnosed as ADs (mean age $73.17 \pm 10.66$ ) according to the 2011 McKhann criteria, as previously described [27, 28]. The UMG-cohort is characterized by neuropsychological testing (Consortium to Establish a Registry for Alzheimer's Disease-CERAD test battery), and AD diagnosis of these 
patients is supported by CSF biomarkers (CSF-NDD) and/ or PET analysis (amyloid PET and/or FDG-PET). The CSF molecular biomarkers (Total-Tau, Phospho-Tau 181, A $\beta 42$ and $\mathrm{A} \beta 42 / \mathrm{A} \beta 40$ ratio) were monitored and cerebral imaging tests were also carried out.

\section{EV Isolation and Characterization}

EVs, with exosome-like characteristics, were isolated from serum samples, as previously described [22, 29, 30]. Two distinct exosome isolation methods were used: the precipitation-based ExoQuick Serum Exosome Precipitation Solution (System Biosciences) (ExoQ) and the column-based ExoSpin Blood Exosome Purification Kit (Cell Guidance Systems) (ExoS). In brief, serum samples were centrifuged to remove cell debris and then incubated with the respective isolation reagent, followed by a centrifugation step to pellet the nanovesicles. For ExoQ, two exosome isolations were performed: one where the EVs were eluted in PBS for transmission electron microscopy (TEM) and Nanoparticle Tracking Analysis (NTA) and the other where the EVs were resuspended in RIPA buffer with protease inhibitors for MS and western blot (WB) analysis. For ExoS, the pellet was resuspended in PBS, passed through a purification column and eluted with PBS. Part of the resulting EVs was used to perform TEM and NTA, while the remaining EV suspension was also mixed with RIPA buffer with protease inhibitors, allowing subsequent analysis. All exosome-enriched suspensions were aliquoted and stored at $-20^{\circ} \mathrm{C}$ prior to analyses. Controls and AD samples were subjected to the same procedure for each $\mathrm{EV}$ isolation method.

The exosome's concentration and size distribution curves were assessed by NTA, using NanoSight NS300 ${ }^{\mathrm{TM}}$ instrument and NTA 3.2 software (Malvern Instruments, UK), as previously described [29]. NTA analysis was carried out in duplicate for each sample, and four video recordings were acquired for each exosome preparation. The particle concentration was corrected by the dilution factor (1:1000).

Exosome-enriched suspensions from both cohorts were randomly selected for TEM analysis. Paraformaldehyde (2\%) was added to the exosome suspensions in PBS, and then exosomes were allowed to adsorb in 75 mesh Formvar/carbon grids. A $3 \%$ phosphotungstic acid solution was added to perform the negative staining. TEM images were obtained using a Hitachi $\mathrm{H}-9000$ transmission electron microscope at $300 \mathrm{kV}$ and images were captured using a slow-scan CCD camera.

The protein concentration of exosomal preparations was determined by BCA protein assay, and $50 \mu \mathrm{g}$ of total protein was loaded from each sample, for sodium dodecyl sulfate polyacrylamide gel electrophoresis (SDS-PAGE). Following gel transfer into a nitrocellulose membrane, immunodetection was carried out for the exosomal markers Hsp70, CD63 and RAB11 and for the negative exosomal marker calnexin.
In brief, membranes were blocked in 5\% non-fat dry milk and incubated with the primary antibodies: anti-HSP70 (1:500) (SPA-812), anti-CD63 (1:500) (sc-5275), anti-RAB11 (1:500) (610657; BD Transduction Laboratories) and anti-Calnexin (1:200) (ADI-SPA-860-J). The secondary antibodies used were the anti-mouse (7076S) or anti-rabbit IgG, HRP-linked antibody (7074S) (Cell Signaling Technology), and protein bands were detected using the chemiluminescence reagent ECL Select (GE Healthcare Life Sciences ${ }^{\mathrm{TM}}$ ). Images were acquired with the ChemiDoc ${ }^{\mathrm{TM}}$ gel imaging system (Bio-Rad).

\section{EV Mass Spectrometry Analysis}

For MS analysis, EVs with exosome-like characteristics were isolated using ExoQ and ExoS. For each method, serum-derived exosomes were isolated from 5 sex- and age-matched Controls (mean age $77.4 \pm 5.41$ ) and 5 clinically diagnosed AD patients (mean age $77.8 \pm 5.59$ ) from the UA-cohort. Subsequent biomarker validation was carried out in a higher number of samples from the UA-cohort and the UMG-cohort.

For MS analyses, EV preparations in RIPA buffer (ExoQ) or PBS plus RIPA buffer (ExoS) were sonicated and protein was quantified through BCA assay, using the Pierce ${ }^{\mathrm{TM}}$ BCA Protein Assay Kit. Loading buffer $(4 \times)$ containing $\beta$-mercaptoethanol was added to exosomal samples, normalized for protein content ( $25 \mu \mathrm{g}$ per sample) and separated in a $5-20 \%$ gradient SDS-PAGE. The resulting gels were stained with Coomassie Blue, and each individual gel lane was excised and divided into smaller fragments, to facilitate sample digestion. The fragment corresponding to the albumin molecular weight (around $66 \mathrm{kDa}$ ) was excluded and thus not analysed by mass spectrometry. The purpose was to reduce biological sample complexity, containing high levels of albumin, which may interfere with detection of other proteins by MS. Gel fragments were washed with ammonium bicarbonate and acetonitrile, and the proteins were reduced with $10 \mathrm{mM}$ DTT $\left(45 \mathrm{~min}\right.$ at $\left.56{ }^{\circ} \mathrm{C}\right)$ and alkylated with $55 \mathrm{mM}$ iodoacetamide ( $30 \mathrm{~min}$ at RT). Then, gel pieces were washed again, allowed to dry and rehydrated in digestion buffer containing $12.5 \mu \mathrm{g} / \mathrm{mL}$ of sequencing grade-modified trypsin in ammonium bicarbonate. Tryptic digestion was performed as previously described [31], with minor modifications. Trypsin was added at an enzyme-to-substrate ratio of $1: 30(\mathrm{w} / \mathrm{w})$ followed by an overnight incubation with $50 \mathrm{mM}$ ammonium bicarbonate at $37^{\circ} \mathrm{C}$. The peptides were extracted by the addition of $5 \%$ formic acid (FA, Fluka) and $5 \% \mathrm{FA} / 50 \%$ ACN (20 min each wash, $2^{\circ} \mathrm{C}$ ) and lyophilized in SpeedVac (Thermo Savant), and peptides were reconstituted in $40 \mu \mathrm{L} 1 \%$ FA solution.

Samples were analysed with a QExactive Orbitrap Mass Spectrometer (Thermo Fisher Scientific, Bremen) through 
the EASY-Spray nano ESI source (Thermo Fisher Scientific, Bremen) that was coupled to an Ultimate 3000 (Dionex, Sunnyvale, CA) HPLC (high-pressure liquid chromatography) system. The trap $(5 \mathrm{~mm} \times 300 \mu \mathrm{m}$ i.d.) and the EASY-spray analytical $(150 \mathrm{~mm} \times 75 \mu \mathrm{m})$ columns used were $\mathrm{C} 18$ PepMap100 (Dionex, LC Packings) having a particle size of $3 \mu \mathrm{m}$. Peptides were trapped at $30 \mu \mathrm{L} / \mathrm{min}$ in $96 \%$ solvent A $(0.1 \%$ FA). Elution was achieved with the solvent B $(0.1 \%$ formic acid $/ 80 \%$ acetonitrile $\mathrm{v} / \mathrm{v})$ at $300 \mathrm{~nL} / \mathrm{min}$. The 92-min gradient used was as follows: 0-3 min, 96\% solvent A; 3-70 min, 4-25\% solvent B; 70-90 min, 25-40\% solvent B; 90-92 min, $90 \%$ solvent B; 90-100 min, $90 \%$ solvent B; 101-120 min, 96\% solvent $\mathrm{A}$. The mass spectrometer was operated at $1.8 \mathrm{kV}$ in the data-dependent acquisition mode. A MS2 method was used with a FT survey scan from 400 to $1600 \mathrm{~m} / \mathrm{z}$ (resolution 70,000; AGC target 1E6). The 10 most intense peaks were subjected to HCD fragmentation (resolution 17,500; AGC target 5E4, NCE 28\%, max. injection time $100 \mathrm{~ms}$, dynamic exclusion $35 \mathrm{~s}$ ).

\section{MS Data Analyses}

Spectra were processed and analysed using Proteome Discoverer (version 2.2, Thermo), with the MS Amanda (version 2.0, University of Applied Sciences Upper Austria, Research Institute of Molecular Pathology) and Sequest HT search engines. The UniProt (TrEMBL and Swiss-Prot) protein sequence database (version of October 2017) was used for all searches under Homo sapiens. The database search parameters were as follows: carbamidomethylation of cysteine, oxidation of methionine and the allowance for up to two missed tryptic cleavages. The peptide mass tolerance was $10 \mathrm{ppm}$, and fragment ion mass tolerance was $0.02 \mathrm{Da}$. To achieve a $1 \%$ false discovery rate, the Percolator (version 2.0, Thermo) node was implemented for a decoy database search strategy and peptides were filtered for high confidence and a minimum length of 6 amino acids, and proteins were filtered for a minimum number of peptide sequences of 1 . The obtained results were further filtered, applying a cutoff at 1.5-fold increase and another at 0.5 -fold decrease. Also, abundances found in less than 2 out of 5 samples were not regarded as being present in the respective condition ( $\mathrm{AD}$ or Control) and, when no abundance was measured for one of the groups of samples, a 100-fold increase/0.01-fold decrease was considered for the ratio.

\section{Bioinformatic Analysis of EVs}

Proteomes obtained by MS (list of gene names from proteins identified) were initially overlapped through Venn diagrams with a serum exosomal gene list (Exo Serum list), obtained from databases and from literature search as described in [30], using the bioinformatics and evolutionary genomics website (http://bioinformatics.psb.ugent.be/webtools/Venn/; accessed on February 3,2020), in order to determine the percentage of exosomal proteins present in EV samples analysed. Only MS proteins for which gene name was available were included in the overlap. From the exosomal proteomes obtained by MS, seven immunoglobulin chains were not included in this analysis since no gene name was available. Additionally, the set of proteins identified for Controls and ADs for each kit by MS (ExoQ and ExoS) was categorized according to their Gene Ontology (GO) annotation, obtained from the UniProtSwiss-Prot database. The GO terms were filtered according to the Generic GO Slim, and categorization was carried out for 'Molecular Function' and 'Biological Process'.

The protein lists identified by MS were then analysed through the use of a dedicated software framework (SysBioTK) as previously reported [2], with the exception of the partial least square (PLS) analysis.

Data was prepared independently for each analysis (AD vs Control for ExoQ; AD vs Control for ExoS). In a first step, the protein abundances obtained from MS were normalized by the median of the protein abundances of the sample. Subsequently, the abundances were independently transformed for each protein in each sample through the use of the binary logarithm. For some proteins, in some samples, there was no abundance data from MS; regardless, these proteins were not removed. The prepared data was then converted into tabular format and exported into a text file, for later use with MetaboAnalyst 4.0 [32] for the PLS analysis (performed on February 11, 2020), in order to maintain a consistent data set. PLS analysis was performed to evaluate which kit had the highest discriminatory capacity between Controls and AD cases.

To identify proteins with statistically significant differences in abundance, a Welch's $t$-test with a significance level of 5\% $(\alpha=0.05)$ was applied to the mean 'normalized and transformed abundance' of the protein in each condition (i.e. the mean across samples for each condition). Volcano plots were created by plotting, for each protein, the p-value of the Welch's $t$-test against the fold increase of the mean 'normalized abundance' of the protein, calculated as the base 2 logarithm of the ratio of the mean normalized abundance in $\mathrm{AD}$ conditions to the mean normalized abundance in Control conditions. The fold change threshold was set to 2 , and a line representing the 5\% significance level was drawn.

Heatmaps were created by taking the "normalized abundance' for each protein in each sample. The dendrograms were calculated using the Ward method to cluster similar samples and proteins together. A Euclidian distance metric was used to calculate the distances for the Ward method. The color scale represents the 'normalized abundance'.

\section{EV Biomarker Candidate Analyses}

Following MS and bioinformatic analysis, biomarker validation was then carried out in a higher number of samples 
from the UA- and the UMG-cohorts. WB analyses were performed to assess the patterns of two biomarker candidates identified by MS: alpha-1-antichymotrypsin (AACT) and $\mathrm{C} 4 \mathrm{~b}$-binding protein alpha chain $(\mathrm{C} 4 \mathrm{BP} \alpha)$. The protein concentration of exosome samples isolated with ExoQ were determined, and $50 \mu \mathrm{g}$ of protein was loaded, per sample, in a 5-20\% SDS-PAGE followed by protein transfer to nitrocellulose membranes. Membranes were then blocked with 5\% non-fat dry milk and incubated with the primary antibodies anti-AACT (1:500) (sc-59430; Santa Cruz Biotechnology) and anti-C4BP $\alpha$ Antibody (1:500) (sc-398720; Santa Cruz Biotechnology). Subsequently, the membranes were incubated with the anti-mouse IgG, HRP-linked antibody (1:2000) (Cell Signaling Technology). Protein bands were detected, as described above, using the chemiluminescence reagent ECL Select (GE Healthcare Life Sciences ${ }^{\mathrm{TM}}$ ), images were acquired with the ChemiDoc ${ }^{\mathrm{TM}}$ gel imaging system (Bio-Rad), and protein bands were quantified using the Image Lab software ( $\mathrm{v}$ 6.0.1, Bio-Rad). AACT or C4BP $\alpha$ band densitometry values for each individual sample were normalized to an exosomal pool loaded in every membrane. Graphs express the relative density ratios. Further, AACT and $\mathrm{C} 4 \mathrm{BP} \alpha$ levels were also evaluated by enzyme-linked immunosorbent assay (ELISA), in serum-derived exosomes of the same individuals, using the commercial Human AACT ELISA Kit (ab217779; Abcam) or the Human C4 binding protein A ELISA Kit (NBP2-60,550; Novus Biologicals), according to manufacturer's instructions. EV samples were diluted, and equal amounts of protein were used for $\mathrm{AACT}$ or $\mathrm{C} 4 \mathrm{BP} \alpha$ quantification.

\section{Statistical Analysis}

Statistical analysis was carried out using SPSS version 27 (IBM) or GraphPad Prism 7 (GraphPad Software, La Jolla, CA, USA). Data distribution was assessed by the Shapiro-Wilk test, and homogeneity of variance was assessed using Levene's test. Kolmogorov-Smirnov was used to compare the particle size distribution. Exosome concentrations were compared using the non-parametric Kruskal-Wallis, and mode sizes were compared by means of a one-way ANOVA with the Bonferroni post hoc test. Levels of biomarker candidates were compared using unpaired $t$-tests. $p$-values $\leq 0.05$ were considered significant.

\section{Results}

\section{EV Isolation from Controls and AD Cases}

Prior to MS analysis, EVs with exosome-like characteristics were isolated from Control and AD cases using two distinct approaches, the precipitation-based (ExoQ) and column-based (ExoS) isolation kits. Exosomes obtained were characterized by Nanoparticle Tracking Analysis (Fig. 1a-c), and size distribution curves revealed that both kits isolated vesicles within the expected size range for exosomes. For ExoQ, no differences were found in the particle concentration between Controls $\left(3.64 \times 10^{11} \pm 2.69 \times 10^{11}\right.$ particles $\left./ \mathrm{mL}\right)$ versus AD cases $\left(3.33 \times 10^{11} \pm 2.81 \times 10^{11}\right.$ particles $\left./ \mathrm{mL}\right)$ or in the mode size between the Control and AD group $(119.5 \pm 17.77 \mathrm{~nm}$ and $122.7 \pm 18.40 \mathrm{~nm}$, respectively) (Fig. 1a-c). In contrast, for ExoS the size distribution of the isolated vesicles and the particle concentration were significantly different $(p \leq 0.05)$ between the Control $\left(6.36 \times 10^{11} \pm 2.49 \times 10^{11}\right.$ particles $/ \mathrm{mL})$ and $\mathrm{AD}\left(4.41 \times 10^{11} \pm 3.15 \times 10^{11}\right.$ particles/ $\mathrm{mL}$ ) groups, although no significant differences were found between the mode size of vesicles isolated from Control $(112.5 \pm 17.32 \mathrm{~nm})$ and $\mathrm{AD}$ groups $(123.3 \pm 28.48 \mathrm{~nm})$. Differences for particle concentrations were also found between the Controls of ExoQ and ExoS and among the four groups $(p \leq 0.001)$. Consistently with NTA, TEM analysis revealed that both methods isolated exosomes with the expected morphology and size (Fig. 1d).

To confirm the nature of the nanovesicles, WB analysis was performed using pooled samples from Controls and AD cases. The exosomal markers HSP70, CD63 and RAB11 were detected in the vesicles isolated using ExoQ and ExoS (Fig. 1e), while the negative exosome marker calnexin was not detected.

\section{GO Analyses of EVs from Controls and AD Cases}

As explained above, serum-derived EVs were isolated from Controls and AD cases using both ExoQ and ExoS and then characterized by MS analysis. ExoQ renders a higher total number of proteins identified by MS when compared to $\operatorname{ExoS}(p \leq 0.01)$. In exosome-like particles isolated with ExoQ, an average of 136 proteins were identified in the Control group and 117 proteins were identified in AD cases. For ExoS, an average of 100 proteins were found in Controls and 85 proteins were identified in ADs (Table 1; Supplementary Tables 1 and 2), including protein isoforms. For both kits, $\mathrm{AD}$ cases presented a small decrease in the number of proteins identified by MS, although not significantly different. The common proteins found in exosomes isolated from Controls and ADs using both ExoQ and ExoS are presented in Supplementary Table 3.

For further analyses, exosomal proteomes obtained through MS (list of gene names from proteins identified) were overlapped with an 'in silico' serum-derived exosomal gene list. This list was collated using public databases, namely Vesiclepedia, EVpedia and Exocarta and 
Fig. 1 Characterization of blood-derived EVs isolated using ExoQ and ExoS. Exosome-like EVs size distribution (a), particle concentration (b) and mode size (c) determined by Nanoparticle Tracking Analysis. d Transmission electron microscopy of isolated nanovesicles and e western blot analysis of the exosomal markers HSP70, CD63 and RAB11. EVs were isolated from UACohort serum samples. Particle concentrations were compared using non-parametric KruskalWallis and mode sizes using one-way ANOVA with Bonferroni post hoc test. Abbreviations: ExoQ, ExoQuick; ExoS, ExoSpin; SH, SH-SY5Y lysates.

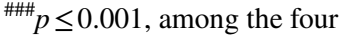
groups; *** $p \leq 0.001$ between Controls of ExoQ and ExoS; $* p \leq 0.05$ between Controls and $\mathrm{AD}$ isolated using ExoS
A.

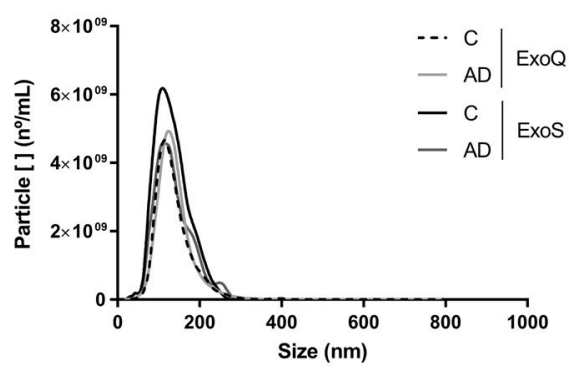

B.

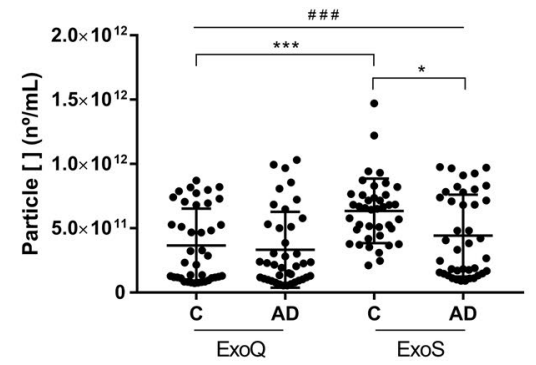

C.

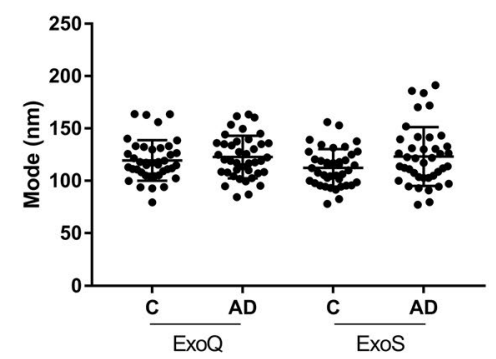

D.

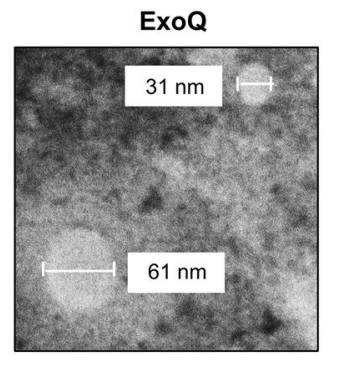

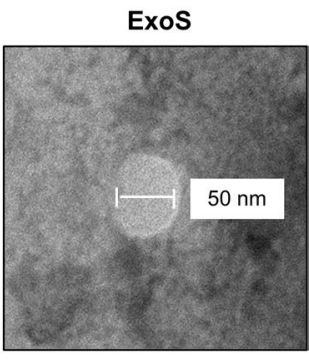

E.
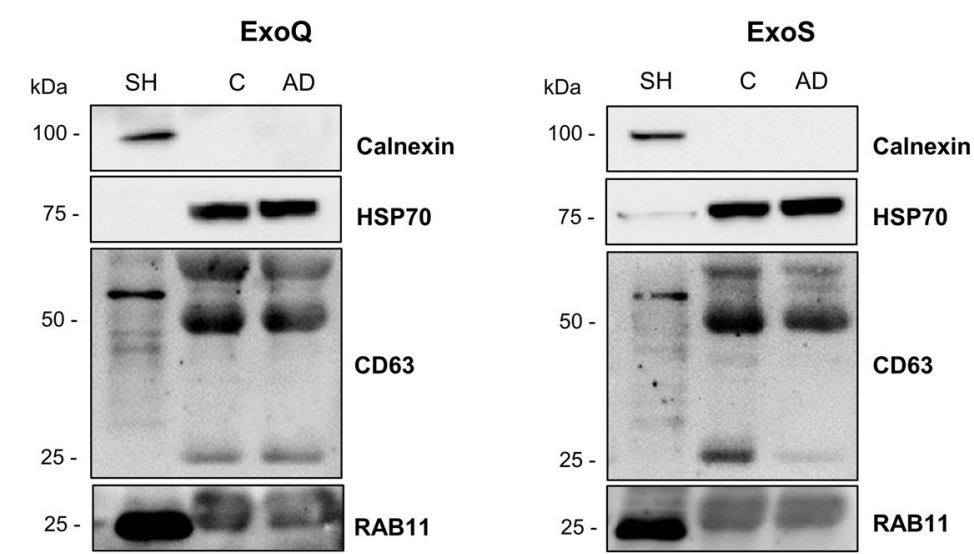

complemented following a literature review on exosomal AD-related proteins [12, 30]. More than $70 \%$ of the exosomal proteins identified by MS and isolated either with ExoQ or ExoS were also present in the serum-derived exosomal gene list, reinforcing the exosomal nature of the samples (Fig. 2; Supplementary Table 4 and 5).

Table 1 Number of exosomal proteins identified by mass spectrometry for both kits. Exosome-like particles were isolated with ExoQ or ExoS, followed by mass spectrometry analysis. Abbreviations: ExoQ, ExoQuick; ExoS, ExoSpin; SD, standard deviation

\begin{tabular}{llllll}
\hline & ExoQ & & & ExoS \\
\cline { 2 - 3 } \cline { 5 - 6 } & Controls & AD & & Controls & AD \\
\hline Mean \pm SD & $136.8 \pm 7.5$ & $117.8 \pm 29.5$ & & $100.2 \pm 8.0$ & $85.8 \pm 16.6$ \\
\hline
\end{tabular}

A.

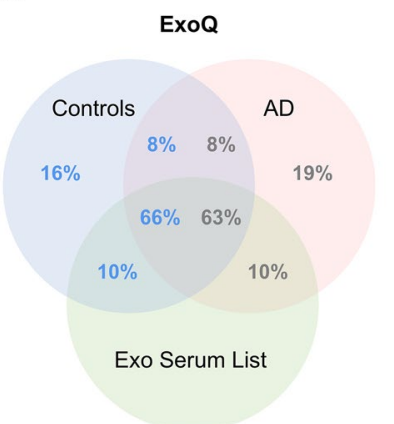

B.

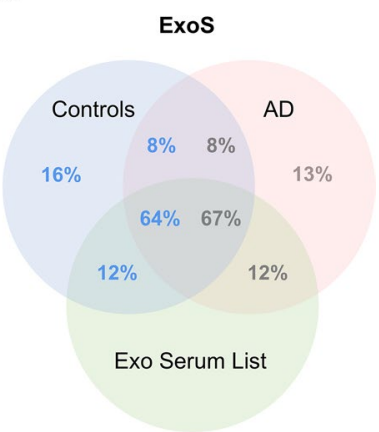

Fig. 2 Overlap of exosomal-enriched proteomes obtained by MS with serum-derived exosomal database recovered list. Venn diagrams illustrating the overlap of the exosomal-enriched proteomes obtained by MS (list of gene names from proteins identified) after exosome isolation from serum samples of the UA-Cohort, using ExoQ (a) and ExoS (b), with the serum exosomal gene list (Exo Serum List) collated from databases and literature search. Abbreviations: ExoQ, ExoQuick; ExoS, ExoSpin 
GO functional enrichment analysis was performed to characterize the exosomal-enriched proteome of Controls and AD cases, obtained with ExoQ (Fig. 3a, b) or ExoS (Fig. 3c, d). The GO terms for molecular function and biological process were similar between Controls and $\mathrm{AD}$ cases of proteomes obtained from both kits. The top 5 molecular function terms

A.

Molecular function - ExoQ

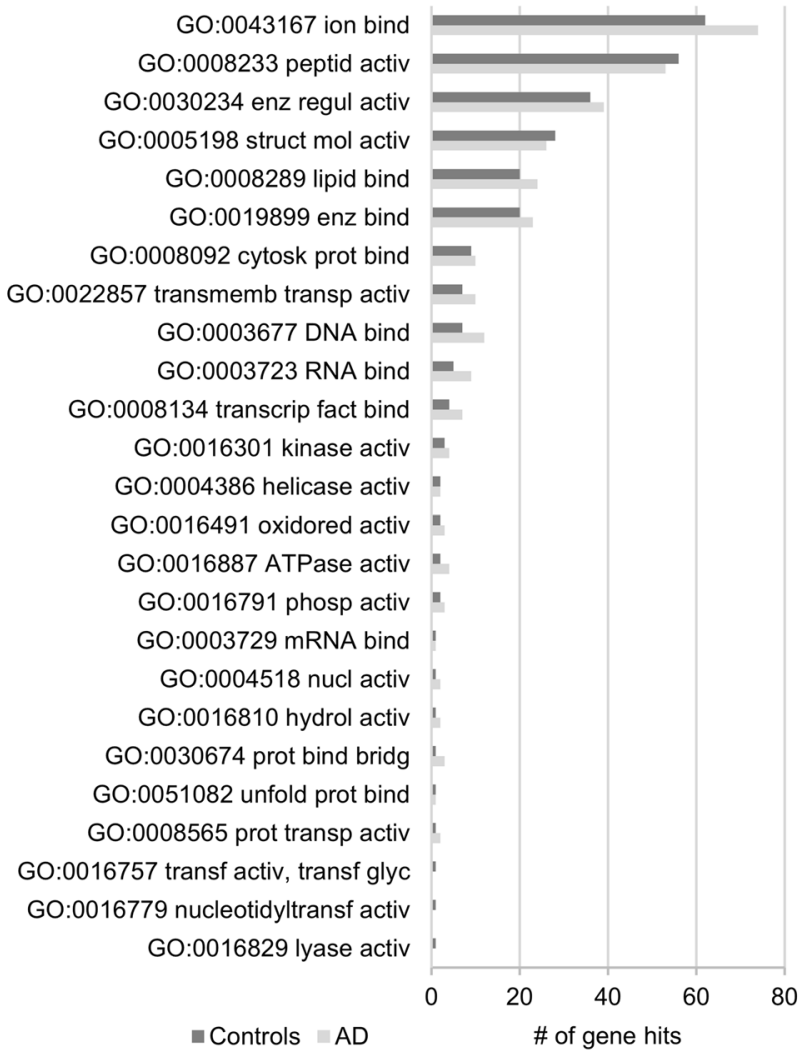

Fig. 3 GO analysis of Controls and AD exosomal-enriched proteomes obtained with ExoQ or ExoS. The top 25 molecular function and biological processes terms were annotated for exosomes isolated from serum samples of the UA-Cohort, with ExoQuick $(\mathbf{a}, \mathbf{b})$ or ExoSpin (c, d). Dark gray bars represent Controls, and light gray bars represent $\mathrm{AD}$ cases. Abbreviations: ExoQ, ExoQuick; ExoS, ExoSpin. Abbreviations of GO molecular function: GO:0043167, ion binding; GO:0008233, peptidase activity; GO:0030234, enzyme regulator activity; GO:0005198, structural molecule activity; GO:0008289, lipid binding; GO:0019899, enzyme binding; GO:0008092, cytoskeletal protein binding; GO:0022857, transmembrane transporter activity; GO:0003677, DNA binding; GO: 0003723, RNA binding; GO:0008134, transcription factor binding; GO:0016301, kinase activity; GO:0004386, helicase activity; GO:0016491, oxidoreductase activity; GO:0016887, ATPase activity; GO:0016791, phosphatase activity; GO:0003729, mRNA binding; GO:0004518, nuclease activity; GO:0016810, hydrolase activity, acting on carbon-nitrogen (but not peptide) bonds; GO: 0030674, protein binding, bridging; GO:0051082, unfolded protein binding; GO:0008565, protein transporter activity; GO:0016757, transferase activity, trans- were ion binding, peptidase activity, enzyme regulator activity, structural molecule activity and lipid binding, whereas the top biological process terms in both cases were immune system process, transport, response to stress, vesicle-mediated transport and signal transduction. In general, ExoQ renders in a higher number of proteins isolated and consequently more

B. Biological process - ExoQ

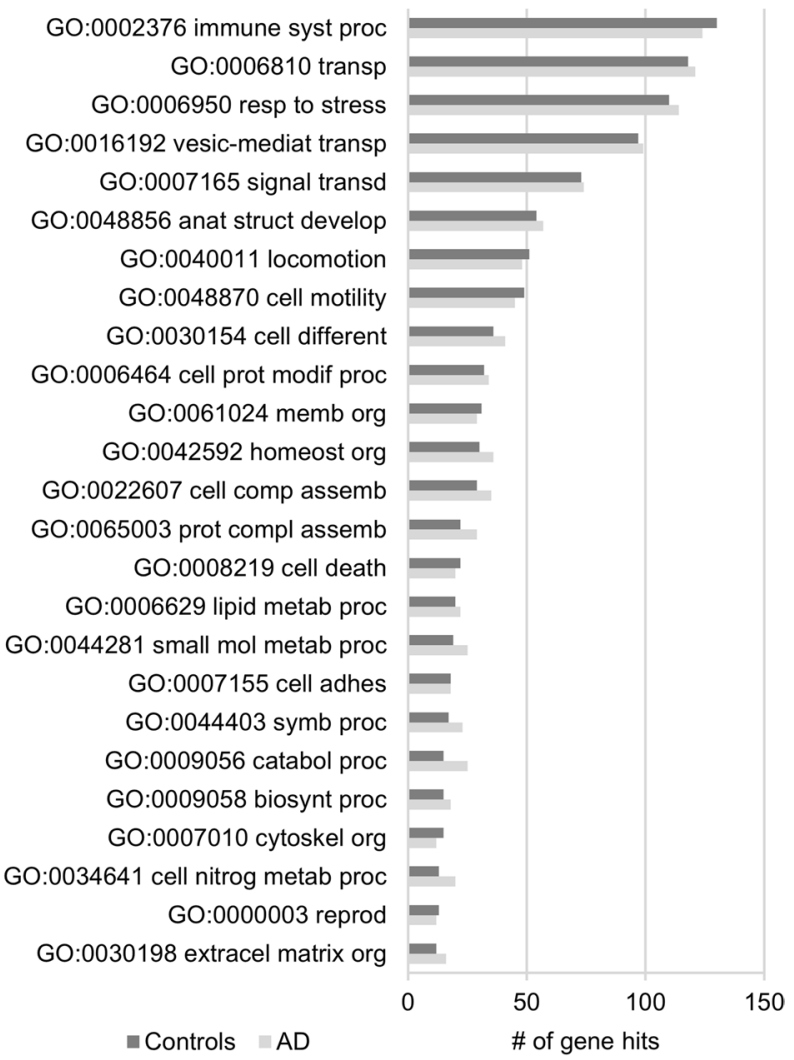

ferring glycosyl groups; GO:0016779, nucleotidyltransferase activity; GO:0016829, lyase activity; GO:0003700, DNA-binding transcription factor activity; GO:0008168, methyltransferase activity; GO:0042393, histone binding. Abbreviations of GO biological process: GO:0002376, immune system process; GO:0006810, transport; GO:0006950, response to stress; GO:0016192, vesicle-mediated transport; GO:0007165, signal transduction; GO:0048856, anatomical structure development; GO:0040011, locomotion; GO:0048870, cell motility; GO:0030154, cell differentiation; GO:0006464, cellular protein modification process; GO:0061024, membrane organization; GO:0042592, homeostatic process; GO:0022607, cellular component assembly; GO:0065003, protein-containing complex assembly; GO:0008219, cell death; GO:0006629 lipid metabolic process; GO:0044281, small molecule metabolic process; GO:0007155, cell adhesion; GO:0044403, symbiont process; GO:0009056, catabolic process; GO:0009058, biosynthetic process; GO:0007010, cytoskeleton organization; GO:0034641, cellular nitrogen compound metabolic process; GO:0000003, reproduction; GO:0030198, extracellular matrix organization; GO:0048646, anatomical structure formation involved in morphogenesis 
C.

Molecular function - ExoS

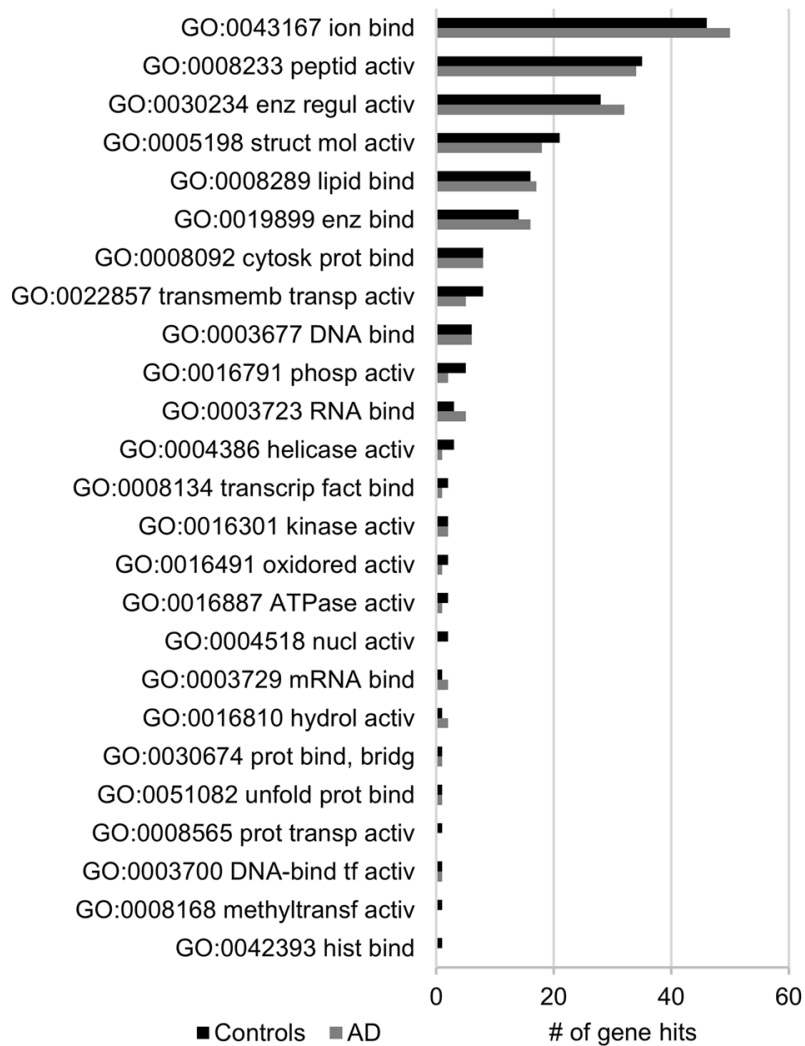

Fig. 3 (continued)

hits for each category. Although not statistically significant, differences in the number of the genes or specific GO terms could be found associated with each kit. These GO proteome differences may be interesting when addressing a particular process and/or approach during biomedical research.
D. Biological process - ExoS

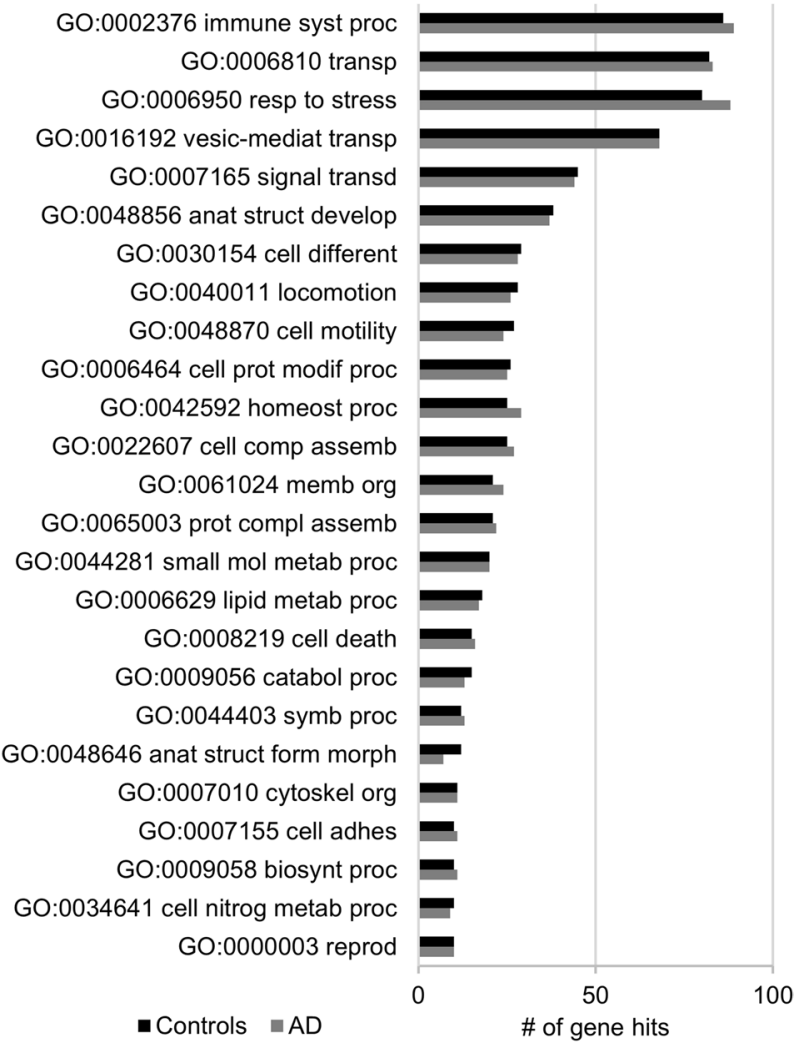

\section{Partial Least Square Analysis of EV Proteomes}

PLS analysis was also carried out to assess and compare the performance of the two kits in discriminating Control and AD cases (Fig. 4). This analysis revealed that ExoQ
Fig. 4 Partial least square analysis of EV proteomes of Controls and AD cases. EV preparations with exosome-like characteristics were isolated with ExoQ (a) or ExoS (b) from serum samples of the UACohort. Green and pink areas represent the $95 \%$ confidence region. Abbreviations: ExoQ, ExoQuick; ExoS, ExoSpin
A.

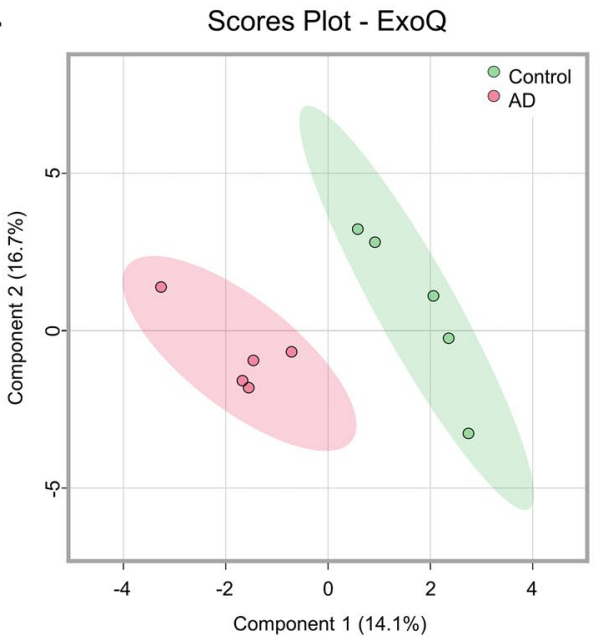

B. Scores Plot - ExoS

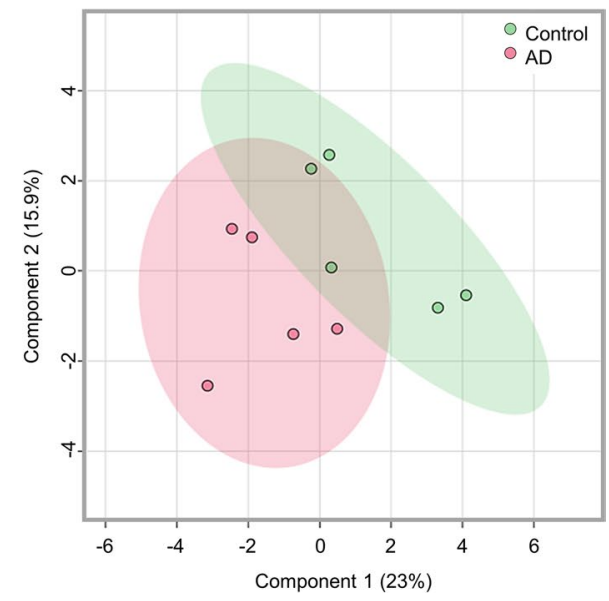


presents a higher discriminatory power, as there was no overlap between Controls and AD cases. Taking this evidence into consideration, and the fact that significant differences were obtained in the number of exosome particles isolated from Controls and AD cases, when using ExoS, subsequent analyses were performed focusing on the results obtained with ExoQ in both groups, AD and Controls. Nonetheless, data obtained for ExoS is also included as supplementary material.

\section{EV Proteomic Signature of Controls and AD Cases}

Heatmaps were constructed to assess which exosomal proteins could potentially be used to discriminate Controls from AD cases. This hierarchical analysis revealed 9 proteins with significantly different abundance levels between Controls and AD cases (Fig. 5).

As depicted in the heatmap and in the volcano plot (Fig. 6), apolipoprotein C-III (APOC3), beta-2-glycoprotein $1(\mathrm{APOH}), \mathrm{C} 4 \mathrm{~b}$-binding protein alpha chain $(\mathrm{C} 4 \mathrm{BP} \alpha)$, Complement $\mathrm{C} 3(\mathrm{CO} 3)$ and immunoglobulin kappa variable 2-30 (KV230) were significantly increased in Control individuals, while alpha-1-antichymotrypsin (AACT) isoform 1, complement component 9 (CO9), immunoglobulin heavy constant mu (IGHM) Isoform 2 and keratin, type II cytoskeletal 6A (K2C6A) were significantly increased in AD cases. Indeed, 6 of these 9 proteins have already been described as altered in the context of $\mathrm{AD}$ (AACT, APOC3, APOH, C4BP $\alpha, \mathrm{CO} 3$ and CO9) (Table 2).

Of the 9 candidates, two were selected for subsequent validation: AACT and C4BP $\alpha$. These were found to be the most interesting candidates since both AACT and C4BP $\alpha$ are detected in senile plaques and both are $\mathrm{A} \beta$-binding proteins [33-36]. AACT can also induce tau phosphorylation [37]. In addition, the patterns of these candidates have been previously addressed in different biofluids, namely CSF, plasma and/or serum. Although some inconsistencies have been observed (Table 2), previous studies reported similar patterns as those obtained here for serum-derived exosomes in MS analysis. Thus, these candidates with opposite expression patterns in Controls and AD cases were further validated by WB and ELISA in exosomes.

Heatmaps were also obtained for the exosomal proteome corresponding to the ExoS method from which 4 proteins showed significant differences for the abundance values among the Controls and AD cases (HV374, ITIH4 isoform 1, THRB and HRG) (Supplementary Fig. 1 and 2, respectively). However, since the disease discriminatory power of this kit was lower than for ExoQ, these candidates were not further pursued.

\section{Validation of the Putative EV Candidates}

To validate the results obtained through MS, the levels of AACT and C4BP $\alpha$ were assessed in exosomal-enriched samples isolated with ExoQ, from both Controls and individuals with dementia, including AD cases, from the UA-cohort and the UMG-cohort. The UA-cohort study group included samples from sex- and aged-matched Controls $(\mathrm{CDR}=0$ and MMSE - , $n=32)$ and individuals with dementia (CDR $\geq 1$ and MMSE,$+ n=32$ ). This dementia group comprises 10 patients that scored $\mathrm{CDR}=1$ and MMSE,+ 22 patients that scored $\mathrm{CDR}=2$ and 3 and MMSE + and 9 clinically diagnosed $\mathrm{AD}$ cases, of which one scored $\mathrm{CDR}=1$, and was also included in the analyses. The UMG-cohort study group included $12 \mathrm{AD}$ cases, characterized by neuropsychological testing and CSF biomarkers and/or imaging analysis, and respective aged-matched Controls. Serum-derived putative exosomal biomarkers were validated using WB analysis and ELISA in both cohorts. For AACT, WB analysis showed a tendency for an increase in dementia cases, for the UA-cohort. The mean exosomal levels of AACT were $1.29 \pm 0.67$ for Controls and $1.65 \pm 1.05$ for CDR $\geq 1$ and MMSE + (Fig. 7a). Regarding AD cases, this tendency was also observed, comparatively to the respective sex- and age-matched Controls, although no statistical significance was evident for the UA-cohort $(1.92 \pm 0.81$ vs $2.14 \pm 1.71$, respectively) (Fig. 7b). However, significant differences were observed for the UMG-cohort, where Controls had lower AACT levels $(1.26 \pm 0.55)$ when compared to the AD group $(2.12 \pm 1.29)(p \leq 0.05)($ Fig. $7 c)$. In accordance, ELISA assays revealed likewise a tendency for increased mean levels of AACT in CDR $\geq 1$ and MMSE + $(11336 \pm 2532 \mathrm{pg} /$ $\mathrm{mL}$ vs $12228 \pm 3274 \mathrm{pg} / \mathrm{mL}$ ) (Fig. $7 \mathrm{~d}$ ), and AD groups from both UA-cohort $(12184 \pm 3280 \mathrm{pg} / \mathrm{mL}$ vs $13948 \pm 4728 \mathrm{pg} /$ $\mathrm{mL})$ (Fig. 7e) and UMG-cohort $(10703 \pm 3114 \mathrm{pg} / \mathrm{mL}$ vs $12035 \pm 4247 \mathrm{pg} / \mathrm{mL}$ ) (Fig. $7 \mathrm{f}$ ), comparatively to the Control groups. As expected, in accordance with the MS analysis results, an opposite pattern was observed for the $\mathrm{C} 4 \mathrm{BP} \alpha$, for both WB and ELISA assays. Comparatively to the Controls, a tendency to lower $\mathrm{C} 4 \mathrm{BP} \alpha$ exosomal levels in the CDR $\geq 1$ and MMSE + group $(1.01 \pm 0.38$ vs $0.86 \pm 0.24$ ) was obtained by WB analysis (Fig. 8a). When considering only the Controls and respective AD cases, C4BP $\alpha$ levels also tend to decrease although with no significant differences $(0.94 \pm 0.19$ and $0.78 \pm 0.19)$ (Fig. 8b). Consistently, a tendency for decreased levels of C4BP $\alpha$ in $\mathrm{AD}$ group $(1.79 \pm 0.75)$ when compared with Controls $(1.72 \pm 0.64)$ was likewise observed for the UMG-cohort (Fig. 8c). Regarding C4BP $\alpha$ ELISA assays, and comparing against respective Controls, decreased mean levels 
Fig. 5 Heatmap of exosomal proteome abundance changes in disease. Heatmaps were constructed for the significantly different proteins identified in exosomes of Controls vs AD cases, isolated from serum samples of the UA-Cohort. Differences were determined using Welch's $t$-test and a 95\% confidence level was considered. The bars on the top of heatmaps show the kits category. Red represents higher abundance and light yellow represents lower abundance levels. Abbreviations: AACT, $\alpha$-1-antichymotrypsin; APOC3, apolipoprotein C-III; APOH, beta-2-glycoprotein 1; C4BPA, $\mathrm{C} 4 \mathrm{~b}$-binding protein alpha chain; $\mathrm{CO} 3$, complement $\mathrm{C} 3$; $\mathrm{CO} 9$, complement component 9; Disease, Alzheimer's disease cases; IGHM, immunoglobulin heavy constant mu; K2C6A, keratin, type II cytoskeletal 6A; KV230, Immunoglobulin kappa variable 2-30

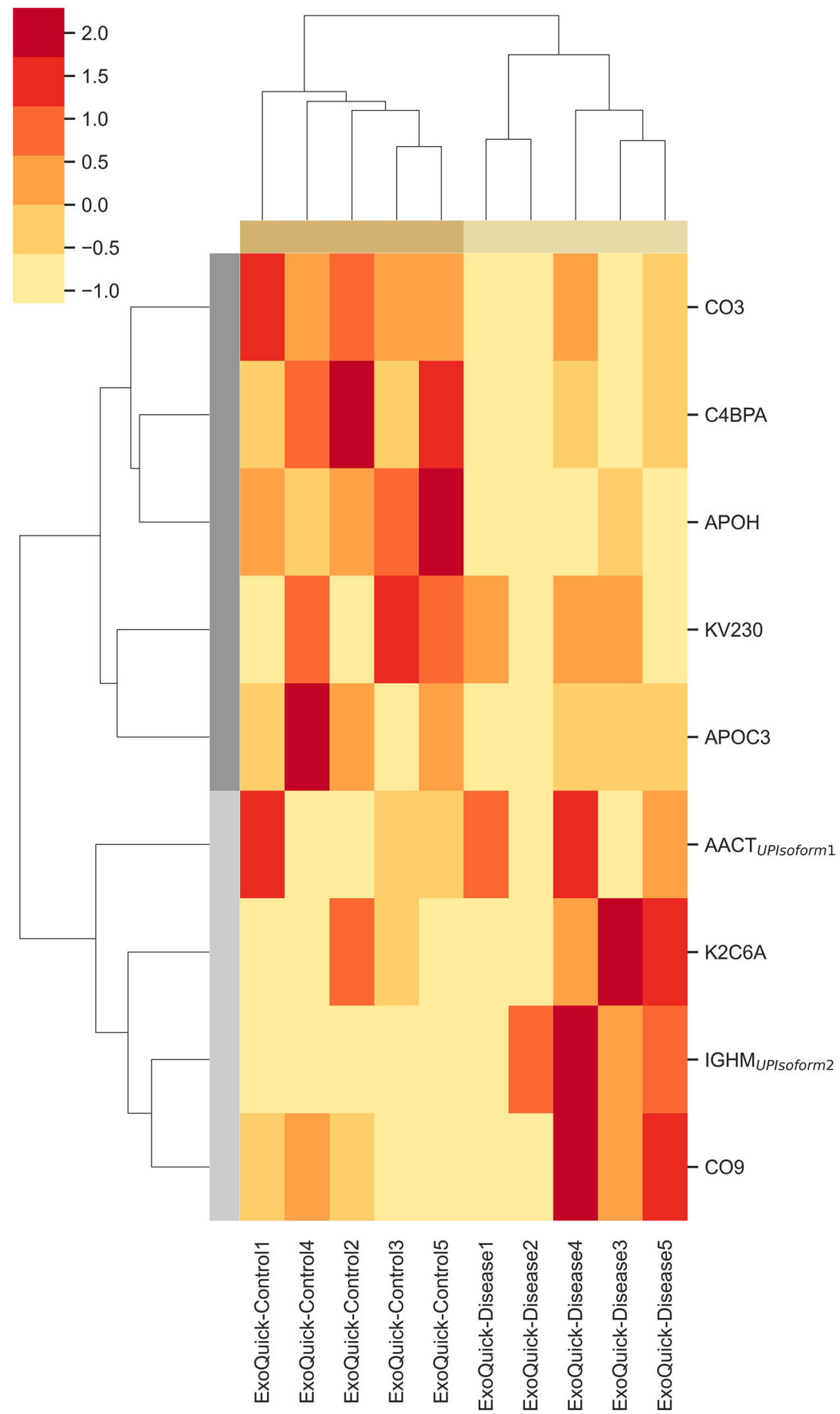




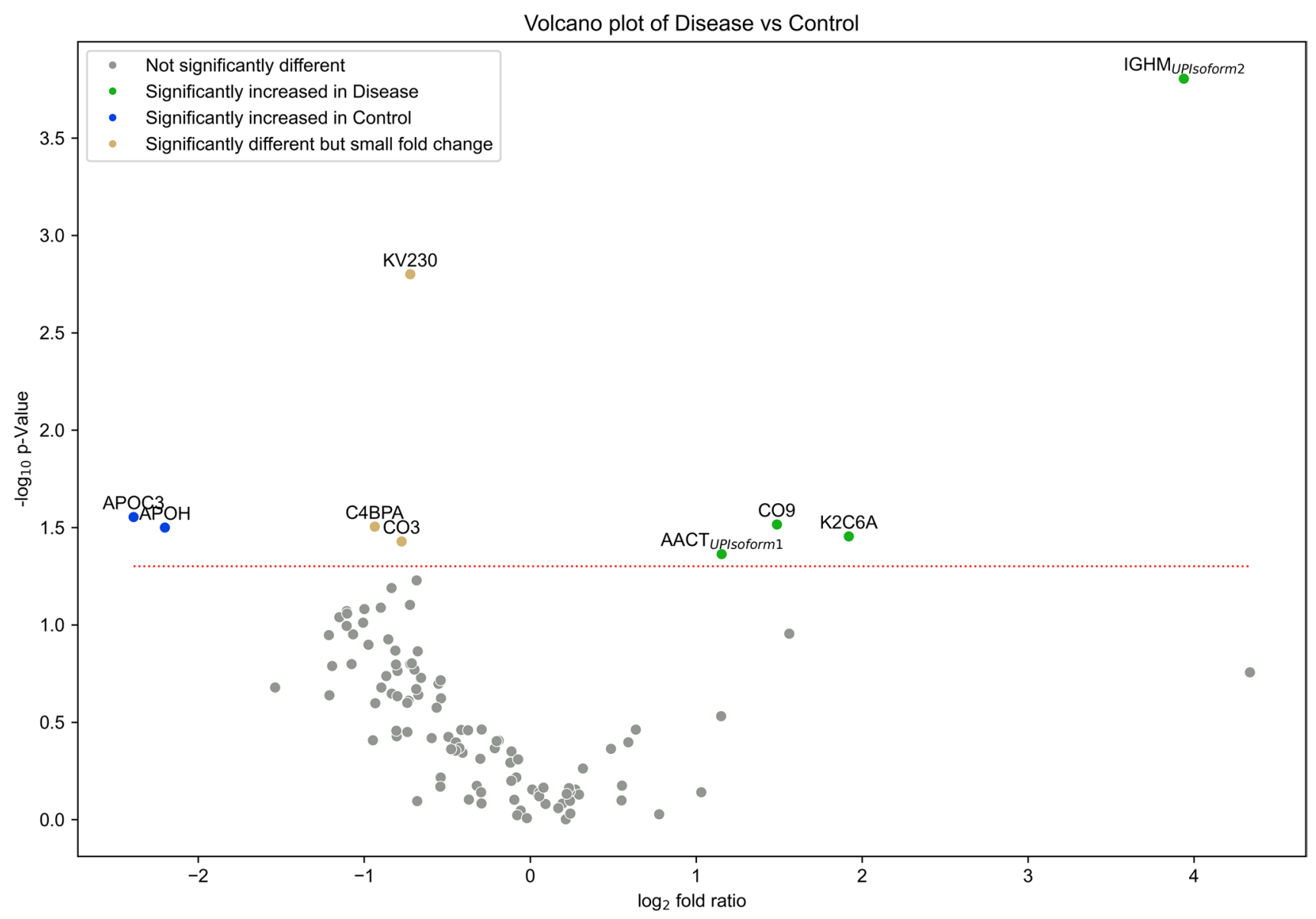

Fig. 6 Volcano plot of significant different exosomal proteins in $\mathrm{AD}$ cases versus Controls. Exosomes were isolated from serumsamples of the UA-Cohort using ExoQuick. The dashed red line indicates the $p$-value threshold of 0.05 . Abbreviations: AACT, $\alpha-1$ antichymotrypsin; APOC3, apolipoprotein C-III; APOH, beta-2-gly-

were obtained for CDR $\geq 1$ and MMSE $+(19.62 \pm 5.41 \mathrm{ng} /$ $\mathrm{mL}$ vs $18.09 \pm 5.17 \mathrm{ng} / \mathrm{mL}$ ) (Fig. 8d), and for ADs from the UA-cohort $(18.77 \pm 4.15 \mathrm{ng} / \mathrm{mL}$ vs $17.95 \pm 6.15 \mathrm{ng} /$ $\mathrm{mL}$ ) (Fig. 8e). For disease cases from the UMG-cohort, this decrease reached statistical significance $(20.13 \pm 5.24 \mathrm{ng} / \mathrm{mL}$ vs $16.51 \pm 2.72 \mathrm{ng} / \mathrm{mL})(p \leq 0.05)$ (Fig. 8f).

\section{Discussion}

AD blood-based biomarker candidates offer less invasive, cheaper and easier alternatives as a first screening tool to set up in clinical settings, or as complementary tools compared to the currently validated biomarker triplet in CSF and imaging approaches. Exosomes have been described as important players in $\mathrm{AD}$ pathogenesis, and these $\mathrm{EVs}$ can be isolated efficiently from blood, thus constituting important resources in the diagnosis of this pathology. In this work, two distinct coprotein 1; C4BPA, C4b-binding protein alpha chain; $\mathrm{CO} 3$, complement C3; CO9, complement component 9; Disease, Alzheimer's disease cases; IGHM, immunoglobulin heavy constant mu; K2C6A, keratin, type II cytoskeletal 6A; KV230, immunoglobulin kappa variable $2-30$

methods (precipitation- and column-based) were employed to isolate serum-derived EVs, with exosome-like characteristics, from Controls and AD cases, and their proteomes were derived through MS and subsequently characterized. Although the size and morphology of the EVs obtained were compatible with the expected exosome features, differences in the particle size distribution and in the number of particles between Controls and AD cases were found for ExoS. Previous studies have reported a tendency for a decreased number of particles in AD cases when compared to Control individuals [14]. Despite that, no significant fluctuations were detected in the number of proteins identified through MS, for exosomes isolated from Controls and AD cases. Further, Control samples from ExoS had a significantly higher particle concentration than Control samples from ExoQ. This may be explained by the different nature of exosome isolation methodologies which can result in different EV subpopulations and yields, and consequently, in distinct 
Table 2 Significant different exosomal proteins and their role in AD. Exosomes were isolated with ExoQ prior to MS analysis

\begin{tabular}{|c|c|c|c|c|c|c|c|}
\hline & UniProt ID & Gene & Protein name & Alteration in $\mathrm{AD}$ & $\begin{array}{l}\text { Involvement in } \mathrm{AD} \\
\text { pathogenesis }\end{array}$ & Biofluid/brain & Reference \\
\hline \multirow[t]{26}{*}{ ExoQ } & \multirow[t]{9}{*}{$\begin{array}{l}\text { P01011-1 (AACT } \\
\text { HUMAN) }\end{array}$} & \multirow[t]{9}{*}{ SERPINA3 } & \multirow[t]{9}{*}{$\alpha$-1-Antichymotrypsin } & $\uparrow$ & \multirow[t]{7}{*}{$\begin{array}{l}\text { Present at amyloid } \\
\text { plaques }\end{array}$} & Human brain & {$[38,42,43,37]$} \\
\hline & & & & $\uparrow$ & & CSF and serum & {$[44,45]$} \\
\hline & & & & $=$ & & CSF and serum & [46-49] \\
\hline & & & & $=$ & & Serum & [50] \\
\hline & & & & $\uparrow$ & & Serum & [51-54] \\
\hline & & & & $\uparrow$ & & CSF and plasma & {$[39,55]$} \\
\hline & & & & $\uparrow$ & & Plasma & {$[56,57]$} \\
\hline & & & & & $\begin{array}{l}\text { Promotes } A \beta \text { plaques } \\
\text { deposition }\end{array}$ & $\begin{array}{l}\text { Transgenic mouse } \\
\text { brain }\end{array}$ & [40] \\
\hline & & & & & $\begin{array}{l}\text { Induce tau hyperphos- } \\
\text { phorylation }\end{array}$ & $\begin{array}{l}\text { Transgenic mouse } \\
\text { brain }\end{array}$ & {$[37,41]$} \\
\hline & $\begin{array}{l}\text { P02656 (APOC3 } \\
\text { HUMAN) }\end{array}$ & APOC3 & Apolipoprotein C-III & $\downarrow$ & & Plasma & {$[58]$} \\
\hline & \multirow{2}{*}{$\begin{array}{l}\text { P02749 (APOH_ } \\
\text { HUMAN) }\end{array}$} & \multirow[t]{2}{*}{$\mathrm{APOH}$} & \multirow[t]{2}{*}{ Beta-2-glycoprotein 1} & $\uparrow$ & & CSF & [59] \\
\hline & & & & $\begin{array}{l}\downarrow \text { in ApoE4 carriers } \\
\text { and MCI individu- } \\
\text { als }\end{array}$ & & Plasma & [60] \\
\hline & \multirow[t]{4}{*}{$\begin{array}{l}\text { P04003 (C4BPA_ } \\
\text { HUMAN) }\end{array}$} & \multirow[t]{4}{*}{ C4BPA } & \multirow[t]{4}{*}{$\begin{array}{l}\text { C4b-binding protein } \\
\text { alpha chain* }\end{array}$} & & $\begin{array}{l}\text { Detected in Abeta } \\
\text { plaques and apop- } \\
\text { totic cells }\end{array}$ & Human brain & {$[33]$} \\
\hline & & & & $=$ & & CSF and plasma & \\
\hline & & & & & $\begin{array}{l}\text { Bind to } \mathrm{A} \beta \text { through } \\
\alpha \text { chain; limits the } \\
\text { complement activa- } \\
\text { tion on } \mathrm{A} \beta \text { peptide }\end{array}$ & In vitro & \\
\hline & & & & $\downarrow$ & & Plasma & [61] \\
\hline & \multirow[t]{4}{*}{$\begin{array}{l}\text { P01024 (CO3_ } \\
\text { HUMAN) }\end{array}$} & \multirow[t]{4}{*}{$\mathrm{C} 3$} & \multirow[t]{4}{*}{ Complement C3 } & $\uparrow$ & & $\begin{array}{l}\text { Human AD brain and } \\
\text { CSF }\end{array}$ & [62] \\
\hline & & & & & $\begin{array}{l}\text { C3 deficiency } \\
\text { protected against } \\
\text { synapse loss and } \\
\text { cognitive decline }\end{array}$ & & {$[63]$} \\
\hline & & & & $\downarrow$ & $\begin{array}{l}\text { Low levels of } \mathrm{C} 3 \\
\text { associated with a } \\
\text { higher risk of } \mathrm{AD}\end{array}$ & Plasma & [64] \\
\hline & & & & $\mathrm{C} 3 \mathrm{~b}, \mathrm{C} 3 \mathrm{~d} \uparrow$ & & $\begin{array}{l}\text { Plasma astrocyte- } \\
\text { derived exosomes }\end{array}$ & {$[17,18]$} \\
\hline & \multirow[t]{3}{*}{$\begin{array}{l}\text { P02748 (CO9_ } \\
\text { HUMAN) }\end{array}$} & \multirow[t]{3}{*}{ C9 } & \multirow[t]{3}{*}{$\begin{array}{l}\text { Complement compo- } \\
\text { nent C9 }\end{array}$} & $\uparrow$ & $\begin{array}{l}\text { Increased number of } \\
\text { C9-stained diffuse } \\
\text { plaques in } \mathrm{AD} \text { vs } \mathrm{C} \\
\text { or MCI }\end{array}$ & $\begin{array}{l}\text { Postmortem human } \\
\text { brain specimens }\end{array}$ & [65] \\
\hline & & & & $\uparrow$ & & Human brain & [66] \\
\hline & & & & C5b-C9 $\uparrow$ & & $\begin{array}{l}\text { Plasma astrocyte- } \\
\text { derived exosomes }\end{array}$ & {$[17,18]$} \\
\hline & $\begin{array}{l}\text { P01871-2 (IGHM_ } \\
\text { HUMAN) }\end{array}$ & IGHM & $\begin{array}{l}\text { Immunoglobulin heavy } \\
\text { constant mu }\end{array}$ & - & - & - & - \\
\hline & $\begin{array}{l}\text { P02538 (K2C6A_ } \\
\text { HUMAN) }\end{array}$ & KRT6A & $\begin{array}{l}\text { Keratin, type II } \\
\text { cytoskeletal 6A }\end{array}$ & - & - & - & - \\
\hline & $\begin{array}{l}\text { P06310 (KV230_ } \\
\text { HUMAN) }\end{array}$ & IGKV2-30 & $\begin{array}{l}\text { Immunoglobulin kappa } \\
\text { variable } 2-30\end{array}$ & - & - & - & - \\
\hline
\end{tabular}

*The information found refers only to $\mathrm{C} 4 \mathrm{BP}$, and it is not specific to the alpha chain

exosome proteomes. In general, ExoQ rendered in a higher number of proteins when compared to the ExoS method, which was not surprising since the latter is a column-based approach, and thus more selective. GO analysis revealed that the top 5 biological processes and functions were similar among Controls and disease cases and also between kits. Nonetheless, differences in the proteomes and the global GO analysis were found and this should be addressed in the 
Fig. 7 AACT exosomal levels in dementia and $\mathrm{AD}$ cases monitored by distinct antibodybased approaches. AACT levels were assessed through immunoblot analysis or commercial ELISA assays in serum-derived exosomes from Controls $(\mathrm{CDR}=0$ and MMSE -$)$ and individuals with dementia $(\mathrm{CDR} \geq 1$ and $\mathrm{MMSE}+$ ) from UA-cohort (a, d), and AD clinically diagnosed cases from UA-cohort (b, e) or UMGcohort (c, f). For WB, each point represents the relative densitometry ratio. For ELISA, each point represents the mean concentration value obtained for each individual. The solid horizontal line shows mean, and error bars indicates standard deviations. Abbreviations: AD, Alzheimer's disease; C, Controls; CDR, Clinical Dementia Rate; MMSE, Mini-Mental State Examination. $* p \leq 0.05$
A.

UA-cohort

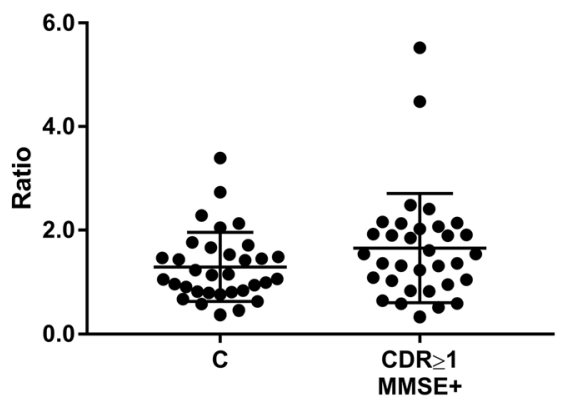

B.

UA-cohort

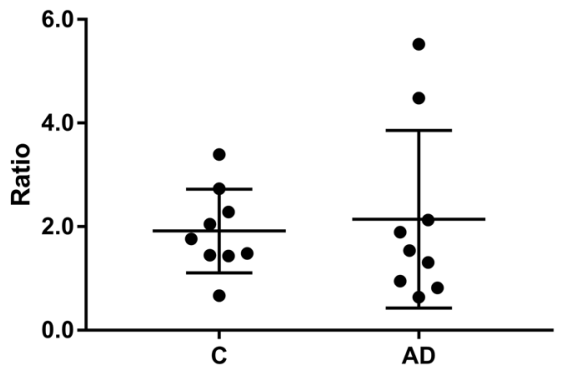

C.

UMG-cohort

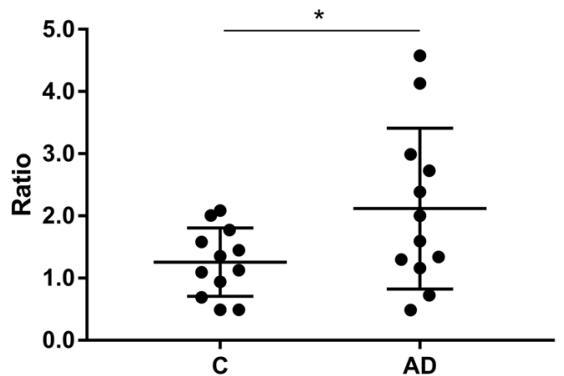

D.

UA-cohort

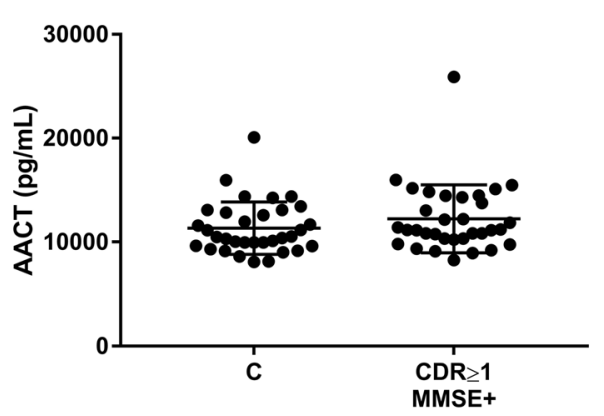

E.

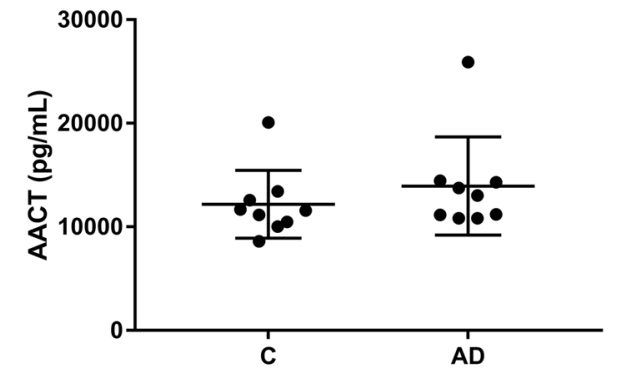

F.

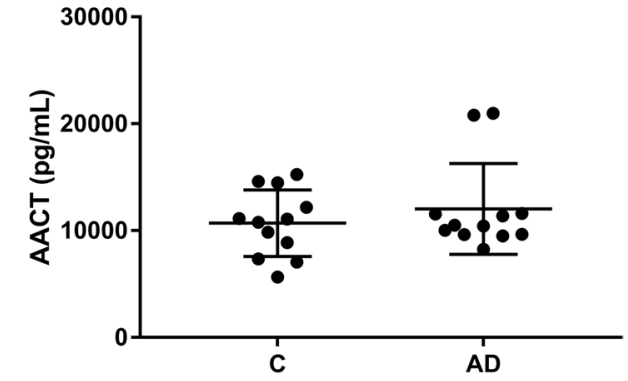

future, since distinct profiles may be relevant when choosing exosome isolation approaches.

PLS analysis revealed that ExoQ had a higher disease discriminatory power than ExoS, and for this reason data obtained with this kit was pursued in more detail. A set of 9 proteins presented significantly different abundance levels between Controls and ADs. APOC3, APOH, C4BP, $\mathrm{CO} 3$ and KV230 were significantly decreased in ADs, whereas AACT Isoform 1, CO9, IGHM Isoform 2 and K2C6A were increased in the exosomes of ADs. Except for IGHM Isoform 2, K2C6A and KV230, all other proteins have previously been linked to $\mathrm{AD}$, and could present disease discriminatory potential, as presented in Table 2. Indeed, both complements $\mathrm{C} 3$ and C5b-C9 have already been tested in plasma astrocyte-derived exosomes [17, 18]. From all identified targets, AACT and $\mathrm{C} 4 \mathrm{BP} \alpha$ were the candidates chosen for follow up studies. $\mathrm{AACT}$ is an interesting target since it binds $\mathrm{A} \beta$, is found in early stages of senile plaques and promotes its deposition and can induce tau phosphorylation, and its levels have been correlated with cognitive test performance [37-41]. C4BP $\alpha$ is another relevant candidate since it binds the $\mathrm{A} \beta$ peptide and can also be found in senile plaques. In addition, it was shown that $\mathrm{C} 4 \mathrm{BP} \alpha$ limits the complement activation by $\mathrm{A} \beta$ and/ or death cells in $\mathrm{AD}$ brains, possibly protecting the neuronal environment from immune activation [33]. Moreover, a previous bioinformatic analysis by our group [30] identified both AACT and C4BP $\alpha$ as $\mathrm{A} \beta$-binding proteins in the exosomal proteome, constructed by the overlap of serum-, plasma- and 
Fig. 8 C4BP $\alpha$ exosomal levels in dementia and $\mathrm{AD}$ cases monitored by distinct antibody-based approaches. C4BP $\alpha$ levels were assessed through immunoblot analysis or commercial ELISA assays in serum-derived exosomes from Controls $(\mathrm{CDR}=0$ and MMSE -) and individuals with dementia $(\mathrm{CDR} \geq 1$ and MMSE +) from UA-cohort (a, d), and AD clinically diagnosed cases from UA-cohort $(\mathbf{b}, \mathbf{e})$ or UMG-cohort (c, f). For WB, each point represents the relative densitometry ratio, and for ELISA, it represents the mean concentration value obtained for each individual. The solid horizontal line shows mean, and error bars indicates standard deviations. Abbreviations: AD, Alzheimer's disease; C, Controls; CDR, Clinical Dementia Rate; MMSE, Mini-Mental State Examination. ${ }^{*} p \leq 0.05$
A.

\section{UA-cohort}

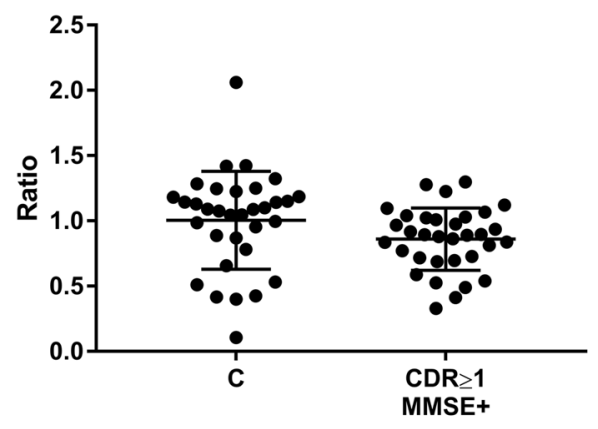

B.

UA-cohort

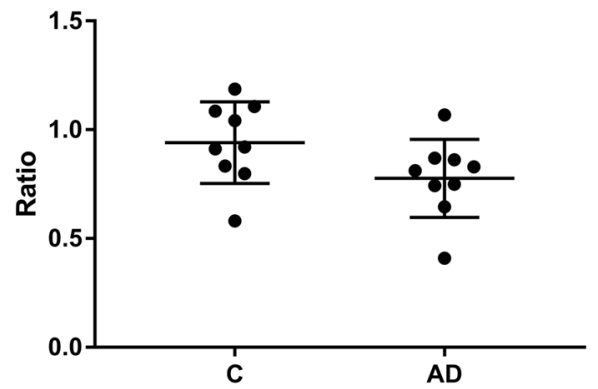

C.

UMG-cohort

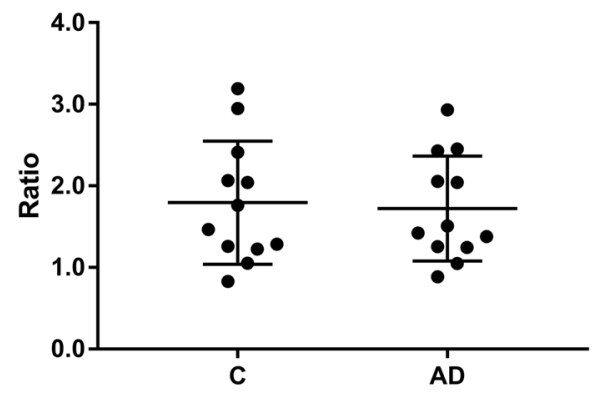

D.

UA-cohort

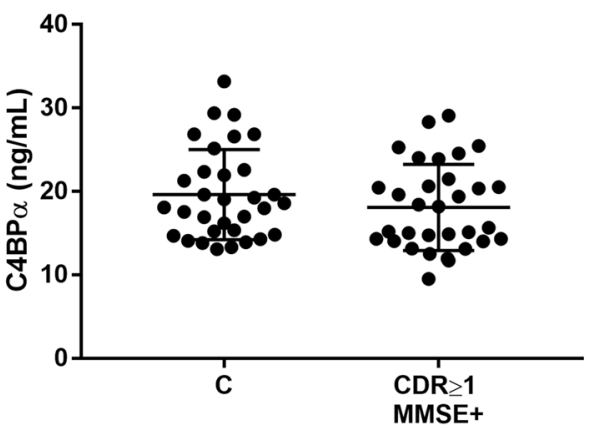

E.

UA-cohort

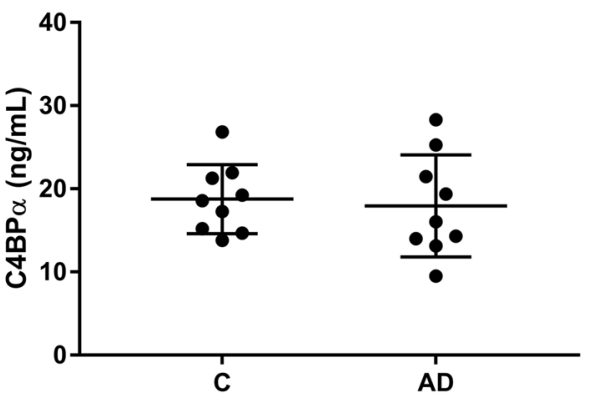

$\mathbf{F}$.

UMG-cohort

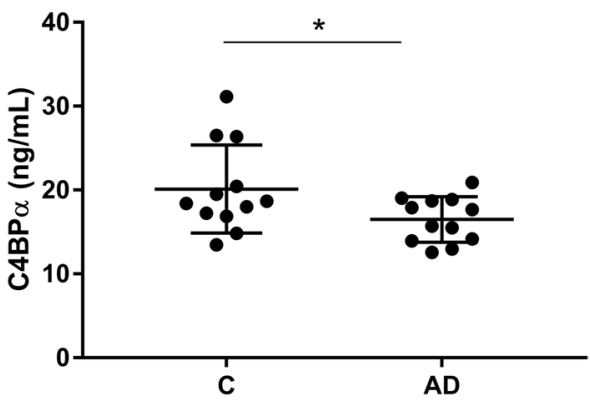

CSF-exosomal proteomes available in databases, namely EXOCARTA, Vesiclepedia or EVpedia. Taken together, we hypothesized that AACT and $\mathrm{C} 4 \mathrm{BP} \alpha$ could represent putative $\mathrm{AD}$ exosomal biomarker candidates, and thus both markers were tested in serum-derived exosomes from Control and $\mathrm{AD}$ cases. Western blot and ELISA approaches were employed to validate $\mathrm{AACT}$ and $\mathrm{C} 4 \mathrm{BP} \alpha$ as putative $\mathrm{AD}$ diagnostic tools. These antibody-based analyses confirmed that the candidate biomarkers, AACT and $\mathrm{C} 4 \mathrm{BP} \alpha$, exhibit variation patterns in agreement with MS results, although significant differences were only found when comparing Controls versus AD cases from the UMG-cohort. This is perhaps not surprising given that the latter was highly characterized by a battery of cognitive and molecular tests. The levels of these proteins have been previously addressed in AD using distinct biofluids (Table 2). Nonetheless, some inconsistencies have been reported, which may relate with the number of individuals enrolled in the study and the distinct techniques used to monitor protein levels. Further, it cannot be excluded that these candidates might also represent early or late-stage biomarkers that alter with disease progression. Indeed, significant correlations were found between AACT exosomal concentrations and MMSE or CDR scores reflecting changes with the cognitive alterations (data not shown). Whether these exosomal biomarkers represent 
potential candidates for $\mathrm{AD}$ diagnosis or general biomarkers for dementia, discriminating the level of cognitive decline, needs to be further validated in a higher number of samples. It would also be interesting to evaluate the levels of these candidates in other neuropathologies, to assess the potential of these two candidates in discriminating $\mathrm{AD}$ from other forms of dementia.

\section{Conclusions}

Novel AD diagnostic markers derived from peripheral biofluids, like blood, are urgently needed. Blood-derived exosomes have recently arisen as a novel source of disease biomarkers. Data presented here identifies new exosome putative targets that could distinguish $\mathrm{AD}$ cases from Controls. Unravelling the exosome proteome in $\mathrm{AD}$ provided a relevant source of blood-based biomarker candidates, easier to implement in clinical practice, which may represent a widely available tool to assist in $\mathrm{AD}$ and/or dementia screening.

\begin{abstract}
Abbreviations AACT: Alpha-1-antichymotrypsin; AD: Alzheimer's disease; $A \beta$ : Amyloid-beta peptide; $\mathrm{C} 4 \mathrm{BP} \alpha$ : $\mathrm{C} 4 \mathrm{~b}$-binding protein alpha chain; CDR: Clinical Dementia Rating; CSF: Cerebrospinal fluid; ELISA: Enzyme-linked immunosorbent assay; ExoQ: ExoQuick; ExoS: ExoSpin; EVs: Extracellular vesicles; GO: Gene Ontology; MMSE: Mini-Mental State Examination; MS: Mass spectrometry; NTA: Nanoparticle tracking analysis; PLS: Partial least square; TEM: Transmission electron microscopy; WB: Western blot
\end{abstract}

Supplementary Information The online version contains supplementary material available at https://doi.org/10.1007/s12035-022-02762-1.

Acknowledgements We thank the volunteers and their families as well as all the health professionals involved in this study.

Author Contribution TSM - conception, design of the work, data acquisition and analysis, interpretation of data, manuscript writing; $\mathrm{RM}$ - data acquisition and manuscript revision; CBCS — data analysis, manuscript writing; JC - data acquisition and manuscript revision; FA — data acquisition, analysis, manuscript revision; TM — data acquisition and analysis; IMR — blood sample collection, pcb-cohort characterization; JV — blood sample collection, UMG-cohort characterization, manuscript revision; JW - blood sample collection, UMGcohort characterization, manuscript revision; OABCS — data analysis and manuscript revision; AGH - conception, design of the work, data acquisition and analysis, interpretation of data, manuscript writing. All authors read and approved the final manuscript.

Funding This work was funded by the Alzheimer's Association under Grant 2019-AARG-644347 and supported by Instituto de Biomedicina (iBiMED) under Grant UIDB/04501/2020; the Fundação para a Ciência e Tecnologia (FCT) of the Ministério da Educação e Ciência, COMPETE program; the QREN and the European Union (Fundo Europeu de Desenvolvimento Regional); and the MEDISIS (CENTRO-01-0246FEDER-000018). JV was funded by the Deutsche Forschungsgemeinschaft (DFG, German Research Foundation) under grant 413501650; TSM is supported by the FCT under the individual PhD grant SFRH/ $\mathrm{BD} / 145979 / 2019$. JW is supported by an Ilídio Pinho professorship at University of Aveiro.
Data availability Data generated or analysed during this study are included in this published article and its supplementary information files.

\section{Declarations}

Ethics Approval and Consent to Participate Sample collection as well as their use in research was approved by the ethics committee for health of the Central Regional Administration of Coimbra (CES da ARS Centro, protocol No. 012804-04.04.2012, Portuguese National Committee for Data Protection (Authorization $N^{\circ} 369 / 2012$ ) for the pcb-cohort, and by the ethics committee of the University Goettingen (9/2/16) for the UMG-cohort. All participants provided written informed consent.

Consent for Publication Not applicable.

Conflict of Interest The authors declare no competing interests.

Open Access This article is licensed under a Creative Commons Attribution 4.0 International License, which permits use, sharing, adaptation, distribution and reproduction in any medium or format, as long as you give appropriate credit to the original author(s) and the source, provide a link to the Creative Commons licence, and indicate if changes were made. The images or other third party material in this article are included in the article's Creative Commons licence, unless indicated otherwise in a credit line to the material. If material is not included in the article's Creative Commons licence and your intended use is not permitted by statutory regulation or exceeds the permitted use, you will need to obtain permission directly from the copyright holder. To view a copy of this licence, visit http://creativecommons.org/licenses/by/4.0/.

\section{References}

1. DeTure MA, Dickson DW (2019) The neuropathological diagnosis of Alzheimer's disease. Mol Neurodegener 14:32. https://doi. org/10.1186/s13024-019-0333-5

2. Henriques AG, Müller T, Oliveira JM, Cova M, da Cruz e Silva CB, da Cruz e Silva OAB (2016) Altered protein phosphorylation as a resource for potential AD biomarkers. Sci Rep 6:30319. https://doi.org/10.1038/srep30319

3. Henriques AG, Oliveira JM, Carvalho LP, da Cruz e Silva OAB (2015) A $\beta$ influences cytoskeletal signaling cascades with consequences to Alzheimer's disease. Mol Neurobiol 52, 1391-1407. https://doi.org/10.1007/s12035-014-8913-4

4. Oliveira J, Costa M, de Almeida MSC, da Cruz e Silva OAB, Henriques AG (2017) Protein phosphorylation is a key mechanism in Alzheimer's disease. J Alzheimer's Dis 58:953-78. https://doi. org/10.3233/JAD-170176

5. Domingues C, da Cruz e Silva OAB, Henriques AG (2017) Impact of cytokines and chemokines on Alzheimer's disease neuropathological hallmarks. Curr Alzheimer Res 14:870-82. https://doi.org/ 10.2174/1567205014666170317113606

6. Blennow K, Zetterberg H (2009) Cerebrospinal fluid biomarkers for Alzheimer's disease. J Alzheimers Dis 18:413-417. https:// doi.org/10.3233/JAD-2009-1177

7. Welge V, Fiege O, Lewczuk P, Mollenhauer B, Esselmann H, Klafki H-W et al (2009) Combined CSF tau, p-tau181 and amyloid- $\beta 38 / 40 / 42$ for diagnosing Alzheimer's disease. J Neural Transm 116:203-212. https://doi.org/10.1007/s00702-008-0177-6

8. Hampel H, O'Bryant SE, Molinuevo JL, Zetterberg H, Masters CL, Lista $\mathrm{S}$ et al (2018) Blood-based biomarkers for Alzheimer 
disease: mapping the road to the clinic. Nat Rev Neurol 14:639652. https://doi.org/10.1038/s41582-018-0079-7

9. Kowal J, Tkach M, Théry C (2014) Biogenesis and secretion of exosomes. Curr Opin Cell Biol 29:116-125. https://doi.org/10. 1016/j.ceb.2014.05.004

10. Armstrong D, Wildman DE (2018) Extracellular vesicles and the promise of continuous liquid biopsies. J Pathol Transl Med 52:1-8. https://doi.org/10.4132/jptm.2017.05.21

11. Kanninen KM, Bister N, Koistinaho J, Malm T (2016) Exosomes as new diagnostic tools in CNS diseases. Biochim Biophys Acta 1862:403-410. https://doi.org/10.1016/j.bbadis.2015.09.020

12. Soares Martins T, Trindade D, Vaz M, Campelo I, Almeida M, Trigo G et al (2020) Diagnostic and therapeutic potential of exosomes in Alzheimer's disease. J Neurochem 156:162-181. https://doi.org/10.1111/jnc. 15112

13. Fiandaca MS, Kapogiannis D, Mapstone M, Boxer A, Eitan E, Schwartz JB et al (2015) Identification of preclinical Alzheimer's disease by a profile of pathogenic proteins in neurally derived blood exosomes: a case-control study. Alzheimers Dement 11:600-7.e1. https://doi.org/10.1016/j.jalz.2014.06.008

14. Goetzl EJ, Mustapic M, Kapogiannis D, Eitan E, Lobach IV, Goetzl L et al (2016) Cargo proteins of plasma astrocyte-derived exosomes in Alzheimer's disease. FASEB J 30:3853-3859. https://doi.org/10.1096/fj.201600756R

15. Kapogiannis D, Mustapic M, Shardell MD, Berkowitz ST, Diehl TC, Spangler RD et al (2019) Association of extracellular vesicle biomarkers with Alzheimer disease in the Baltimore longitudinal study of aging. JAMA Neurol 76:1340-1351. https://doi.org/10. 1001/jamaneurol.2019.2462

16. Goetzl EJ, Kapogiannis D, Schwartz JB, Lobach IV, Goetzl L, Abner EL et al (2016) Decreased synaptic proteins in neuronal exosomes of frontotemporal dementia and Alzheimer's disease. FASEB J 30:4141-4148. https://doi.org/10.1096/fj.201600816R

17. Goetzl EJ, Schwartz JB, Abner EL, Jicha GA, Kapogiannis D (2018) High complement levels in astrocyte-derived exosomes of Alzheimer disease. Ann Neurol 83:544-552. https://doi.org/ 10.1002/ana. 25172

18. Winston CN, Goetzl EJ, Schwartz JB, Elahi FM, Rissman RA (2019) Complement protein levels in plasma astrocyte-derived exosomes are abnormal in conversion from mild cognitive impairment to Alzheimer's disease dementia. Alzheimers Dement (Amst) 11:61-66. https://doi.org/10.1016/j.dadm.2018.11.002

19. Winston CN, Goetzl EJ, Akers JC, Carter BS, Rockenstein EM, Galasko D et al (2016) Prediction of conversion from mild cognitive impairment to dementia with neuronally derived blood exosome protein profile. Alzheimers Dement (Amst) 3:63-72. https:// doi.org/10.1016/j.dadm.2016.04.001

20. Cheng L, Doecke JD, Sharples RA, Villemagne VL, Fowler CJ, Rembach A et al (2015) Prognostic serum miRNA biomarkers associated with Alzheimer's disease shows concordance with neuropsychological and neuroimaging assessment. Mol Psychiatry 20:1188-1196. https://doi.org/10.1038/mp.2014.127

21. Lugli G, Cohen AM, Bennett DA, Shah RC, Fields CJ, Hernandez AG et al (2015) Plasma exosomal miRNAs in persons with and without Alzheimer disease: altered expression and prospects for biomarkers. PLoS ONE 10:e0139233. https://doi.org/10.1371/ journal.pone.0139233

22. Soares Martins T, Magalhães S, Rosa IM, Vogelgsang J, Wiltfang J, Delgadillo I et al (2020) Potential of FTIR spectroscopy applied to exosomes for Alzheimer's disease discrimination: a pilot study. J Alzheimer's Dis 74:391-405. https://doi.org/10.3233/ JAD-191034

23. Su H, Rustam YH, Masters CL, Makalic E, McLean CA, Hill AF et al (2021) Characterization of brain-derived extracellular vesicle lipids in Alzheimer's disease. J Extracell Vesicles 10:e12089. https://doi.org/10.1002/jev2.12089
24. Oeckl P, Otto M (2019) A review on MS-based blood biomarkers for Alzheimer's disease. Neurol Ther 8:113-127. https://doi.org/ 10.1007/s40120-019-00165-4

25. Rosa IM, Henriques AG, Carvalho L, Oliveira J, da Cruz e Silva OAB (2017) Screening younger individuals in a primary care setting flags putative dementia cases and correlates gastrointestinal diseases with poor cognitive performance. Dement Geriatr Cogn Disord 43:15-28. https://doi.org/10.1159/000452485

26. Rosa IM, Henriques AG, Wiltfang J, da Cruz E, Silva OAB (2018) Putative dementia cases fluctuate as a function of mini-mental state examination cut-off points. J Alzheimers Dis 61:157-167. https://doi.org/10.3233/JAD-170501

27. Shahpasand-Kroner H, Klafki H-W, Bauer C, Schuchhardt J, Hüttenrauch M, Stazi M et al (2018) A two-step immunoassay for the simultaneous assessment of $A \beta 38, A \beta 40$ and $A \beta 42$ in human blood plasma supports the $\mathrm{A} \beta 42 / \mathrm{A} \beta 40$ ratio as a promising biomarker candidate of Alzheimer's disease. Alzheimers Res Ther 10:121. https://doi.org/10.1186/s13195-018-0448-x

28. Vogelgsang J, Shahpasand-Kroner H, Vogelgsang R, Streit F, Vukovich R, Wiltfang J (2018) Multiplex immunoassay measurement of amyloid- $\beta 42$ to amyloid- $\beta 40$ ratio in plasma discriminates between dementia due to Alzheimer's disease and dementia not due to Alzheimer's disease. Exp Brain Res 236:1241-1250. https://doi.org/10.1007/s00221-018-5210-x

29. Soares Martins T, Catita J, Martins Rosa I, da Cruz e Silva O.A.B., Henriques AG (2018) Exosome isolation from distinct biofluids using precipitation and column-based approaches. PLoS One 13:e0198820. https://doi.org/10.1371/journal.pone.0198820

30. Soares Martins T, Marçalo R, Ferreira M, Vaz M, Silva RM, Rosa IM et al (2021) Exosomal A $\beta$-binding proteins identified by "in silico" analysis represent putative blood-derived biomarker candidates for alzheimer's disease. Int J Mol Sci 22:3933. https://doi. org/10.3390/ijms 22083933

31. Shevchenko A, Tomas H, Havlis J, Olsen JV, Mann M (2007) Ingel digestion for mass spectrometric characterization of proteins and proteomes. Nat Protoc 1:2856-2860. https://doi.org/10.1038/ nprot. 2006.468

32. Chong J, Wishart DS, Xia J (2019) Using MetaboAnalyst 4.0 for comprehensive and integrative metabolomics data analysis. Curr Protoc Bioinforma 68:e86. https://doi.org/10.1002/cpbi.86

33. Trouw LA, Nielsen HM, Minthon L, Londos E, Landberg G, Veerhuis R et al (2008) C4b-binding protein in Alzheimer's disease: binding to Abeta1-42 and to dead cells. Mol Immunol 45:36493660. https://doi.org/10.1016/j.molimm.2008.04.025

34. Fraser PE, Nguyen JT, McLachlan DR, Abraham CR, Kirschner DA (1993) Alpha 1-antichymotrypsin binding to Alzheimer A $\beta$ peptides is sequence specific and induces fibril disaggregation in vitro. J Neurochem 61:298-305. https://doi.org/10.1111/j.14714159.1993.tb03568.x

35. Gollin PA, Kalaria RN, Eikelenboom P, Rozemuller A, Perry G (1992) $\alpha 1$-Antitrypsin and $\alpha 1$-antichymotrypsin are in the lesions of Alzheimer's disease. NeuroReport 3:201-203. https://doi.org/ 10.1097/00001756-199202000-00020

36. Sun YX, Wright HT, Janciauskiene S (2002) $\alpha 1$-antichymotrypsin/ Alzheimer's peptide A $\beta 1-42$ complex perturbs lipid metabolism and activates transcription factors PPAR $\gamma$ and $\mathrm{NF \kappa B}$ in human neuroblastoma (Kelly) cells. J Neurosci Res 67:511-522. https:// doi.org/10.1002/jnr.10144

37. Padmanabhan J, Levy M, Dickson DW, Potter H (2006) Alpha1antichymotrypsin, an inflammatory protein overexpressed in Alzheimer's disease brain, induces tau phosphorylation in neurons. Brain 129:3020-3034. https://doi.org/10.1093/brain/awl255

38. Vanni S, Moda F, Zattoni M, Bistaffa E, De Cecco E, Rossi $M$ et al (2017) Differential overexpression of SERPINA3 in human prion diseases. Sci Rep 7:15637. https://doi.org/10.1038/ s41598-017-15778-8 
39. DeKosky ST, Ikonomovic MD, Wang X, Farlow M, Wisniewski S, Lopez OL et al (2003) Plasma and cerebrospinal fluid $\alpha 1$-antichymotrypsin levels in Alzheimer's disease: Correlation with cognitive impairment. Ann Neurol 53:81-90. https://doi.org/ 10.1002/ana. 10414

40. Nilsson LNGG, Bales KR, DiCarlo G, Gordon MN, Morgan D, Paul SM et al (2001) $\alpha$-1-Antichymotrypsin promotes $\beta$-sheet amyloid plaque deposition in a transgenic mouse model of Alzheimer's disease. J Neurosci 21:1444-1451. https://doi.org/10. 1523/JNEUROSCI.21-05-01444.2001

41. Tyagi E, Fiorelli T, Norden M, Padmanabhan J (2013) Alpha 1-antichymotrypsin, an inflammatory protein overexpressed in the brains of patients with Alzheimer's disease, induces tau hyperphosphorylation through c-Jun N-terminal kinase activation. Int J Alzheimers Dis 2013:606083. https://doi.org/10.1155/2013/606083

42. Abraham CR, Selkoe DJ, Potter H (1988) Immunochemical identification of the serine protease inhibitor $\alpha 1$-antichymotrypsin in the brain amyloid deposits of Alzheimer's disease. Cell 52:487-501. https://doi.org/10.1016/0092-8674(88)90462-X

43. Licastro F, Mallory M, Hansen LA, Masliah E (1998) Increased levels of $\alpha$-1-antichymotrypsin in brains of patients with Alzheimer's disease correlate with activated astrocytes and are affected by APOE 4 genotype. J Neuroimmunol 88:105-110. https://doi. org/10.1016/S0165-5728(98)00096-4

44. Licastro F, Parnetti L, Morini M, Davis L, Cucinotta D, Gaiti A et al (1995) Acute phase reactant alpha 1-antichymotrypsin is increased in cerebrospinal fluid and serum of patients with probable Alzheimer disease. Alzheimer Dis Assoc Disord 9:112-118. https://doi.org/10.1097/00002093-199509020-00009

45. Matsubara E, Hirai S, Amari M, Shoji M, Yamaguchi H, Okamoto $\mathrm{K}$ et al (1990) $\alpha 1$-Antichymotrypsin as a possible biochemical marker for Alzheimer-type dementia. Ann Neurol 28:561-567. https://doi.org/10.1002/ana.410280414

46. Delamarche C, Berger F, Gallard L, Pouplard-Barthelaix A (1991) Aging and Alzheimer's disease: protease inhibitors in cerebrospinal fluid. Neurobiol Aging 12:71-74. https://doi.org/10.1016/ 0197-4580(91)90042-i

47. Furby A, Leys D, Delacourte A, Buee L, Soetaert G, Petit H (1991) Are alpha-1-antichymotrypsin and inter-alpha-trypsin inhibitor peripheral markers of Alzheimer's disease? J Neurol Neurosurg Psychiatry 54:469. https://doi.org/10.1136/jnnp.54.5.469

48. Pirttila T, Mehta PD, Frey H, Wisniewski HM (1994) $\alpha 1$-Antichymotrypsin and IL- $1 \beta$ are not increased in CSF or serum in Alzheimer's disease. Neurobiol Aging 15:313-317. https://doi. org/10.1016/0197-4580(94)90026-4

49. Lanzrein AS, Johnston CM, Perry VH, Jobst KA, King EM, Smith AD (1998) Longitudinal study of inflammatory factors in serum, cerebrospinal fluid, and brain tissue in Alzheimer disease: Interleukin-1 $\beta$, interleukin-6, interleukin-1 receptor antagonist, tumor necrosis factor- $\alpha$, the soluble tumor necrosis factor receptors I and I. Alzheimer Dis Assoc Disord 12:215-227. https://doi. org/10.1097/00002093-199809000-00016

50. Lawlor BA, Swanwick GRJ, Feighery C, Walsh JB, Coakley D (1996) Acute phase reactants in Alzheimer's disease. Biol Psychiatry 39:1051-1052. https://doi.org/10.1016/0006-3223(95) 00426-2

51. Matsubara E, Amari M, Shoji M, Harigaya Y, Yamaguchi H, Okamoto K et al (1989) Serum concentration of alpha 1-antichymotrypsin is elevated in patients with senile dementia of the Alzheimer type. Prog Clin Biol Res 317:707-714

52. Brugge K, Katzman R, Hill LR, Hansen LA, Saitoh T (1992) Serological $\alpha 1$-antichymotrypsin in Down's syndrome and Alzheimer's disease. Ann Neurol 32:193-197. https://doi.org/10.1002/ ana.410320211
53. Altstiel LD, Lawlor B, Mohs R, Schmeidler J, Dalton A, Mehta P et al (1995) Elevated alpha1-antichymotrypsin serum levels in a subset of nondemented first-degree relatives of Alzheimer's disease patients. Dement Geriatr Cogn Disord 6:17-20. https://doi. org/10.1159/000106917

54. Lieberman J, Schleissner L, Tachiki KH, Kling AS (1995) Serum $\alpha 1$-antichymotrypsin level as a marker for Alzheimer-type dementia. Neurobiol Aging 16:747-753. https://doi.org/10.1016/01974580(95)00056-k

55. Nielsen HM, Minthon L, Londos E, Blennow K, Miranda E, Perez $\mathrm{J}$ et al (2007) Plasma and CSF serpins in Alzheimer disease and dementia with Lewy bodies. Neurology 69:1569-1579. https:// doi.org/10.1212/01.wnl.0000271077.82508.a0

56. Porcellini E, Davis E, Chiappelli M, Ianni E, Di Stefano G, Forti P et al (2008) Elevated plasma levels of alpha-1-anti-chymotrypsin in age-related cognitive decline and Alzheimers disease: a potential therapeutic target. Curr Pharm Des 14:2659-2664. https://doi. org/10.2174/138161208786264151

57. Licastro F, Pedrini S, Caputo L, Annoni G, Davis LJ, Ferri C et al (2000) Increased plasma levels of interleukin-1, interleukin-6 and $\alpha-1$-antichymotrypsin in patients with Alzheimer's disease: peripheral inflammation or signals from the brain? J Neuroimmunol 103(97-102):738. https://doi.org/10.1016/S0165-5728(99) 00226-X

58. Shih Y-HH, Tsai K-JJ, Lee C-WW, Shiesh S-CC, Chen W-TT, Pai $\mathrm{M}-\mathrm{CC}$ et al (2014) Apolipoprotein C-III is an amyloid- $\beta$-binding protein and an early marker for Alzheimer's disease. J Alzheimers Dis 41:855-865. https://doi.org/10.3233/JAD-140111

59. Öhrfelt A, Andreasson U, Simon A, Zetterberg H, Edman A, Potter W et al (2011) Screening for new biomarkers for subcortical vascular dementia and Alzheimer's disease. Dement Geriatr Cogn Dis Extra 1:31-42. https://doi.org/10.1159/000323417

60. Fei S, Anne P, John C, Nicole AK, Wei W, Barbara C et al (2012) Plasma apolipoprotein levels are associated with cognitive status and decline in a community cohort of older individuals. PLoS ONE 7:e34078. https://doi.org/10.1371/journal.pone.0034078

61. Song F, Poljak A, Kochan NA, Raftery M, Brodaty H, Smythe GA et al (2014) Plasma protein profiling of mild cognitive impairment and Alzheimer's disease using iTRAQ quantitative proteomics. Proteome Sci 12:5. https://doi.org/10.1186/1477-5956-12-5

62. Wu T, Dejanovic B, Gandham VD, Gogineni A, Edmonds R, Schauer S et al (2019) Complement C3 is activated in human AD brain and is required for neurodegeneration in mouse models of amyloidosis and tauopathy. Cell Rep 28:2111-2123.e6. https://doi. org/10.1016/j.celrep.2019.07.060

63. Shi Q, Chowdhury S, Ma R, Le KX, Hong S, Caldarone BJ, et al (2017) Complement C3 deficiency protects against neurodegeneration in aged plaque-rich APP/PS1 mice. Sci Transl Med 9:eaaf6295. https://doi.org/10.1126/scitranslmed.aaf6295

64. Rasmussen KL, Nordestgaard BG, Frikke-Schmidt R, Nielsen SF (2018) An updated Alzheimer hypothesis: complement C3 and risk of Alzheimer's disease - a cohort study of 95,442 individuals. Alzheimer's Dement 14:1589-1601. https://doi.org/10.1016/j.jalz. 2018.07.223

65. Loeffler DA, Camp DM, Bennett DA (2008) Plaque complement activation and cognitive loss in Alzheimer's disease. J Neuroinflammation 5:9. https://doi.org/10.1186/1742-2094-5-9

66. Yasojima K, Schwab C, McGeer EG, McGeer PL (1999) Upregulated production and activation of the complement system in Alzheimer's disease brain. Am J Pathol 154:927-936. https://doi. org/10.1016/S0002-9440(10)65340-0

Publisher's Note Springer Nature remains neutral with regard to jurisdictional claims in published maps and institutional affiliations. 